\title{
SP75 is encoded by the DP87 gene and belongs to a family of modular Dictyostelium discoideum outer layer spore coat proteins
}

\author{
Christopher M. West, ${ }^{1}$ Jie Mao, ${ }^{1}$ Hanke van der Wel, ${ }^{1}$ Gregory W. Erdos ${ }^{2}$ \\ and Yunyan Zhang'
}

Author for correspondence: Christopher M. West. Tel: +1352 3923329. Fax: + 13523923305.
e-mail: westcm@anatomy.med.ufl.edu

Department of Anatomy and Cell Biology, College of Medicine', and Interdisciplinary Center for Biotechnology Research?2 University of Florida, Gainesville, FL 32610-0235, USA

\begin{abstract}
Highly purified spore coats of Dictyostelium discoideum each contained about $5 \times 10^{6}$ protein molecules as determined by amino acid composition analysis. By two-dimensional gel electrophoresis the coats were found to contain nine major-abundance and numerous minor protein species, most of which were highly enriched relative to the adjacent interspore matrix. Protein was nearly quantitatively eluted by denaturants and 2-mercaptoethanol, showing that it was not irreversibly cross-linked. Because a reducing agent is required together with denaturants to elute most proteins if their free thiol groups have been prealkylated, it was concluded that the $D$. discoideum spore coat proteins are disulfide cross-linked into the matrix. One major coat protein, SP75, was partially sequenced and found to be encoded by the previously identified DP87 gene; this finding was supported by additional physical, genetic, biochemical and microscopic evidence. The five major proteins for which genes have been cloned were associated with the outer layer of the coat. In coats missing one or more of four of these proteins as a result of gene disruption, there were physical changes but, with one exception, the other major coat proteins appeared to be incorporated normally. Sequence analysis showed that these five outer layer coat proteins are homologous and consist of alternating sequence motifs related to epithelial mucin repeats, basic proline repeats found in salivary acidic proline-rich proteins, the $\mathbf{N H}_{\mathbf{2}}$-terminal subdomain of epidermal growth factor modules and other cysteine repeats. Based on these and other observations, outer layer coat proteins are predicted to organize indeterminately to form a cell surface microenvironment supportive of cellulose morphogenesis during spore coat formation.
\end{abstract}

Keywords: Dictyostelium discoideum, spore coat proteins, mucins, EGF-repeats, basic proline repeats

\section{INTRODUCTION}

The Dictyostelium discoideum spore coat, a $210 \mathrm{~nm}$ thick layer of protein and polysaccharide at the spore cell surface, constitutes an elastic (Lydan \& Cotter, 1994) physical barrier that constrains osmotic swelling of the amoeba and protects it from exposure to external agents. The coat forms a permeability barrier to protein-sized molecules, but not to water and other small molecules (Cotter, 1981; West \& Erdos, 1990). Coat formation is

Abbreviations: MSH, 2-mercaptoethanol; IAA, iodoacetamide; EGF, epidermal growth factor. initiated by secretion of stored protein into a soluble pool at the cell surface. As cellulose is subsequently deposited, outer and inner layers of protein become organized around a middle zone of cellulose (West \& Erdos, 1990, 1992; Freeze, 1995). As previously suggested (Wilkinson \& Hames, 1983) and confirmed in this paper, disulfide bonds appear to stablilize the coat via intermolecular cross-links in addition to probably stabilizing protein folding. Some intermolecular disulfide cross-links may be established prior to secretion from the prespore vesicle (Devine et al., 1983; Watson et al., 1993, 1994), though it is not clear to what extent observed cross-links were the result of the propensity, shown here, of coat protein 
disulfide bonds to migrate and exchange in the presence of denaturing agents.

Since five of the coat genes have been cloned (Fosnaugh \& Loomis, 1989a, b; Tasaka et al., 1990; Haberstroh \& Firtel, 1990; Yoder et al., 1994), it is possible to genetically probe the role of protein in coat formation. Deletion of each of three genes encoding proteins of the outer layer results in a coat more permeable to a protein tracer (Fosnaugh et al., 1995). Strains lacking all three proteins have the highest permeability (Fosnaugh et al., 1995), germinate more efficiently and have a lower buoyant density (this report). This study shows that the DP87 gene (Ozaki et al., 1993) encodes another outer-layer-associated coat protein, SP75, allowing an analysis of the role of this protein in a DP87 gene disruption strain. However, in none of these mutant strains was the overall protein composition of the remaining coat examined. The role of protein in the coat has also been examined in $\bmod B$ and fucosylation mutants, in which specific protein glycosylation pathways are disrupted. These mutants have spore coats that are more permeable and have higher buoyant densities than those of the wild-type (Gonzalez-Yanes $e t$ al., 1989; Aparicio et al., 1990). The results indicate that coat proteins have an important role in coat permeability, exerted either during coat assembly or in the final structure.

Multiple spore coat proteins have been identified (Devine et al., 1982, 1983; Wilkinson \& Hames, 1983; West \& Erdos, 1988; Yoder et al., 1994), but the number and relative abundance of these proteins are not known. The present study establishes that coat proteins can be quantitatively extracted from the coat for two-dimensional gel electrophoretic analysis. Highly purified coats contain nine abundant protein species, and even the most protein-deficient gene disruption mutant incorporates and expresses substantial levels of all but one of the coat protein species. The result is consistent with an indeterminate rather than a crystalline lattice arrangement of outer layer proteins in the coat. Examination of the sequences of five of the abundant outer layer coat proteins not only confirms a common ancestry but also suggests that they consist of mucin-like, basic proline and epidermal growth factor (EGF)-like motifs. Thus, the outer layer of the coat consists of modular proteins with mucinlike properties that conform to the indeterminate type of organization suggested above.

\section{METHODS}

Cells. Strain TL56 is a derivative of the normal strain Ax3 of Dictyostelium discoideum in which the genes $\cot A, \cot B$ and $\cot C$ (Table 1) have been disrupted by insertion of the pyr 5,6 gene (Fosnaugh et al., 1995). Strain DP87 $7^{-}$is a derivative of Ax2 in which the DP87 gene has been disrupted (Nakao et al., 1994). Strain $\mathrm{PspB}^{-}$is a derivative of $\mathrm{Ax} 4$ in which the $p s p B$ gene has been disrupted (Powell-Coffman \& Firtel, 1994). According to our confirmatory RNA and DNA blot analyses, $p s p B$ is a singlecopy gene which is disrupted in the clone provided by J. PowellCoffman (data not shown). Cells were passaged axenically in HL-5, or on lawns of Klebsiella aerogenes grown on SM agar plates (Aparicio et al., 1990). To prepare spores on an analytical scale, fruiting bodies were allowed to differentiate on lawns of $K$. aerogenes. For extraction of spores, 1 -d-old sori were collected with a loop into $1 \mathrm{ml}$ of $\mathrm{KP}$ buffer $\left(10 \mathrm{mM} \mathrm{KH}_{2} \mathrm{PO}_{4} / \mathrm{NaOH}\right.$, $\mathrm{pH} 6.5)$. Spores were recovered by centrifugation at $12000 \mathrm{~g}$ for $10 \mathrm{~s}$, resuspended in $\mathrm{H}_{2} \mathrm{O}$, and counted in a haemacytometer. Interspore matrix was recovered by concentrating the supernatant in a vacuum centrifuge. For germination, 1-d-old spores were transferred to the lid by slapping the inverted Petri plate onto a counter top, and recovered by jetting KP/NP-40 [KP supplemented with $0.02 \%(\mathrm{v} / \mathrm{v})$ NP-40] onto the surface and collecting the suspension by decanting (Aparicio et al., 1990). Contamination by stalks was reduced by vacuum filtration through a 120 -mesh steel screen. For preparative-scale spore preparations from which proteins were to be purified, approximately $10^{11}$ axenically grown cells were washed first in water, resuspended in PDF $(20 \mathrm{mM} \mathrm{KCl}, 45 \mathrm{mM}$ sodium phosphate, $6 \mathrm{mM} \mathrm{MgSO}, \mathrm{pH} 5.8$ ), and plated onto $46 \times 57 \mathrm{~cm}$ sheets of filter paper composites, consisting of one sheet of Whatman no. 50 paper layered on top of two sheets of Whatman no. 3 paper, each premoistened with PDF. After 1-2 d incubation in a covered chamber, fruiting bodies were collected by scraping with the edge of a spatula, suspended in approximately $200 \mathrm{ml}$ $\mathrm{KP} / \mathrm{NP}-40$, and vacuum-filtered through a 120 -mesh screen. The resulting spore suspension was washed in KP by centrifugation.

Preparation of spore coats. Spores were recovered from $K$. aerogenes lawns and germination was induced by incubation at $45^{\circ} \mathrm{C}$ for $30 \mathrm{~min}$. Coats were purified by differential centrifugation and density gradient centrifugation as described previously (Aparicio et al., 1990). Buoyant density was estimated from the isopycnic position of the centre of the coat band in the tube. Coats were removed from the gradient by needle puncture of the centrifuge tube wall, diluted with KP buffer into polypropylene microcentrifuge tubes, counted in a haemacytometer, and pelleted in the cold. The supernatant was aspirated and the pellets were stored at $-80^{\circ} \mathrm{C}$. Since coats tend to adsorb to the wall of the tube, the entire tube contents were utilized for each procedure.

Extraction of spores for amino acid composition analysis. Coats from approximately $10^{9}$ spores were resuspended in $1 \mathrm{ml}$ $8 \mathrm{M}$ urea, $20 \mathrm{mM}$ Tris $/ \mathrm{HCl}(\mathrm{pH} 7 \cdot 5), 5 \%$ (v/v) MSH (2mercaptoethanol) using a probe sonifier and heated in a boiling water bath for $5 \mathrm{~min}$. Residual spore coats were recovered by centrifugation. The supernatants were transferred to new polypropylene microcentrifuge tubes and precipitated with 5 vols ice-cold acetone. Protein was recovered by centrifugation and washed with $80 \%(\mathrm{v} / \mathrm{v})$ cold acetone (referred to as the 'urea extract'). The residual spore coat pellets were washed twice with water. For further extraction, coats were resuspended in $2 \%(\mathrm{w} / \mathrm{v}) \mathrm{SDS}, 20 \mathrm{mM}$ Tris $/ \mathrm{HCl}(\mathrm{pH} 7 \cdot 5), 5 \% \mathrm{MSH}$ using a bath sonifier and heated in a boiling water bath for $5 \mathrm{~min}$. The residual spore coats were recovered by centrifugation and washed twice with water. The supernatants were transferred to new polypropylene microcentrifuge tubes and precipitated with 5 vols ice-cold acetone. Protein was recovered by centrifugation and washed with $80 \%$ cold acetone (referred to as the "SDS extract').

Amino acid analysis. Duplicate preparations of samples were hydrolysed in $6 \mathrm{M} \mathrm{HCl}$ at $110^{\circ} \mathrm{C}$ for $20 \mathrm{~h}$, and analysed by a ninhydrin method (Ploug et al., 1989). Values for Trp, Cys and Met were calculated from their proportions in five spore coat proteins of known amino acid composition (see Table 2).

Serial extraction of spores for SDSPAGE analysis. Spores were picked with a wire loop and suspended in $1 \mathrm{ml}$ of water. After counting in a haemacytometer, the spores were collected by 
Table 1. Properties of spores and spore coats in various strains of $D$. discoideum

\begin{tabular}{|c|c|c|c|c|}
\hline Strain* & $\begin{array}{l}\text { Disrupted } \\
\text { gene(s) }\end{array}$ & $\begin{array}{l}\text { Protein(s) } \\
\text { affected }\end{array}$ & $\begin{array}{c}\text { Percentage } \\
\text { germination } \dagger\end{array}$ & $\begin{array}{c}\text { Spore coat } \\
\text { buoyant density }\end{array}$ \\
\hline$A \times 3$ & None & None & 48 & $1 \cdot 306$ \\
\hline $\mathrm{X} 22^{a}$ & None & None & 50 & - \\
\hline WS $308 B^{a}$ & None & $\begin{array}{l}\text { SP85 and SP86 } \\
\text { polymorphisms }\end{array}$ & - & $1 \cdot 302$ \\
\hline WS576 ${ }^{a}$ & None & $\begin{array}{l}\text { SP85 and SP86 } \\
\text { polymorphisms }\end{array}$ & - & $1 \cdot 301$ \\
\hline $\mathrm{PspB}^{-b}$ & $p s p B$ & None & - & $1 \cdot 298$ \\
\hline \multirow[t]{3}{*}{ TL56 } & $\cot A$ & $\mathrm{SP} 96^{-}$ & 84 & $1 \cdot 285$ \\
\hline & $\cot B$ & $\mathrm{SP} 70^{-}$ & & \\
\hline & $\cot C$ & $\mathrm{SP} 60^{-}$ & & \\
\hline $\mathrm{DP} 87^{-d}$ & $\cot D(\mathrm{DP} 87)$ & $\mathrm{SP} 75^{-}$ & 56 & $1 \cdot 277$ \\
\hline
\end{tabular}

- , Not determined.

* Strains were generously provided by : a, A. Champion and K. Williams, Macquarie University, Sydney, Australia ; $b$, J. Coffman-Powell and R. Firtel, University of California, San Diego, USA; $c$, K. Fosnaugh and W. F. Loomis, University of California, San Diego, USA; $d$, M. Tasaka and I. Takeuchi, Kyoto University, Japan and National Institute for Basic Biology, Okazaki, Japan, respectively.

t After heat activation for $30 \mathrm{~min}$ at $45^{\circ} \mathrm{C}$.

centrifugation at $12000 \mathrm{~g}$ for $10 \mathrm{~s}$ and resuspended in $8 \mathrm{M}$ urea, $20 \mathrm{mM}$ Tris $/ \mathrm{HCl}(\mathrm{pH} \mathrm{7 \cdot 4}$ ), containing $1 \mathrm{mM}$ PMSF, $10 \mu \mathrm{g}$ leupeptin $\mathrm{ml}^{-1}$ and $18.5 \mu \mathrm{g}$ aprotinin $\mathrm{ml}^{-1}$, to give $3.3 \times 10^{7}$ cells $\mathrm{ml}^{-1}$. They were vortexed and kept at $22^{\circ} \mathrm{C}$ for $15-30 \mathrm{~min}$ before being collected as above. The same volume of the supplemented $8 \mathrm{M}$ urea solution was mixed with the pellet by vortexing, and the suspension was heated in boiling water for 3 min. Extracted spores were recovered by centrifugation, then serially extracted as above with $2 \%$ SDS in $20 \mathrm{mM}$ Tris $/ \mathrm{HCl}$ $(\mathrm{pH} 7 \cdot 4$ ) at room temperature, hot $2 \% \mathrm{SDS}$ in $20 \mathrm{mM}$ Tris $/ \mathrm{HCl}$ (pH 7.4), and hot $2 \% \mathrm{SDS} / 5 \% \mathrm{MSH}$ in $20 \mathrm{mM}$ Tris $/ \mathrm{HCl}(\mathrm{pH}$ 7.4). The solutions of some extraction series were supplemented with $5 \% \mathrm{MSH}$ and $5 \mathrm{mM}$ ED'TA, or $5 \% \mathrm{MSH}$ and $5 \mathrm{mM}$ EDTA. Where indicated, spores were prealkylated with $100 \mathrm{mM}$ iodoacetamide (IAA) during the initial water wash using conditions which prevented formation of artifactual disulfide bonds during isolation of gap junction connexon proteins from tissues (Dupont $e t$ al., 1989; John \& Revel, 1991).

Purification and sequencing of SP75. Approximately $10^{11}$ spores collected as described above were resuspended at $5 \times 10^{8} \mathrm{ml}^{-1}$ in $8 \mathrm{M}$ urea, $5 \% \mathrm{MSH}, 10 \mathrm{mM} \mathrm{NH} \mathrm{NCO}_{3}$ $(\mathrm{pH} 6.0)$ and heated for $5 \mathrm{~min}$ in a boiling-water bath. After centrifugation $(10000 \mathrm{~g}$ for $10 \mathrm{~min})$, the supernatant was chromatographed on a TSK DEAE-5PW HPLC column (Gonzalez-Yanes $e$ t al., 1989). Fractions were analysed by SDSPAGE and immunoblotting. SP75 was identified from its apparent $M_{\mathrm{r}}$ and binding of $\mathrm{mAb} 83.5$. After staining the gel with Coomassie Blue, the polyacrylamide fragment containing SP75 was excised and the protein was digested with endoproteinase Lys-C, essentially as described by Stone \& Williams (1993). The digestion product and undigested protein were separated in a SDS-PAGE gel using a Tris/Tricine buffer system, immunoblotted onto Immobilon- $\mathrm{P}^{\mathrm{sQ}}$ membranes and subjected to Edman degradation as described previously (Kozarov et al., 1995).

Gel electrophoresis and immunoblotting. For standard onedimensional SDS-PAGE, samples were either diluted in concentrated sample buffer or dissolved in normal strength sample buffer and applied to a 7-20\% linear polyacrylamide gradient gel using the Laemmli buffer system, as modified by West \& Erdos (1992). For two-dimensional gel electrophoresis, spore coats and interspore matrix, previously dried in a vacuum centrifuge, were solubilized and resolved as described by Gonzalez-Yanes et al. (1989). Sample loading was based on spore coat number or on the number of spore coats with which the amount of interspore matrix loaded was originally associated. Gels were stained with Coomassie Brilliant Blue (Gonzalez-Yanes et al., 1989) or by a silver method (Wray et al., 1981). For immunoprobing, gels were electroblotted onto $0.45 \mu \mathrm{m}$ pore diameter nitrocellulose paper using an apparatus consisting of parallel steel and graphite plates (Idea Scientific), or a semidry apparatus (Bio-Rad). The blotting buffer was Laemmli electrophoresis buffer diluted with $0 \cdot 25 \mathrm{vol}$. methanol, and electroblotting was carried out at room temperature for $2-3 \mathrm{~h}$ at a current of $200 \mathrm{~mA}$. Blots were immunoprobed as described by West \& Erdos (1992).

Electron microscopic analysis. Samples were prepared and visualized as previously described for material to be immunoprobed (West \& Erdos, 1992).

DP87 gene mapping. cDp87-1, kindly provided by M. Tasaka, was amplified and the DP87 coding insert was supplied to Drs A. Kuspa and W. F. Loomis for restriction enzyme mediated insertion (REMI)-RFLP mapping (Kuspa \& Loomis, 1994). As described previously (Ozaki et al., 1993), cDp87-1 is encoded by a unique gene as determined by Southern blotting (data not shown).

\section{RESULTS}

\section{Protein can be quantitatively extracted from the spore coat}

To determine the amount of protein in the spore coat, the amino acid content was quantified after acid hydrolysis. Values for amino acids not determined by the method were extrapolated from the cDNA-derived amino acid composition of five known spore coat proteins (Table 2, column 4). This approach estimates $0.52 \mathrm{pg}$ protein per 
Table 2. Amino acid composition of spores, coats, coat extracts and known coat proteins

\begin{tabular}{|c|c|c|c|c|c|c|c|}
\hline \multirow{3}{*}{$\begin{array}{l}\text { Amino } \\
\text { acid }\end{array}$} & \multicolumn{7}{|c|}{ Amino acid content (pmol per $10^{6}$ units)* } \\
\hline & \multirow[t]{2}{*}{ Spores } & \multicolumn{2}{|c|}{ Spore coats $\dagger$} & \multicolumn{2}{|c|}{ Urea extraction $\dagger$} & \multicolumn{2}{|c|}{ SDS/urea extraction $\dagger$} \\
\hline & & Total & 5 proteins $\ddagger$ & Residue & Extract & Residue & Extract \\
\hline Asp/Asn & $10200(10 \cdot 2)$ & $556(11 \cdot 6)$ & $(11 \cdot 4)$ & $75 \cdot 0(11 \cdot 6)$ & $418(11 \cdot 7)$ & $6 \cdot 8(9 \cdot 16)$ & $-\delta$ \\
\hline Thr & $6040(6.00)$ & $365(7.59)$ & $(8 \cdot 37)$ & $45 \cdot 4(6 \cdot 25)$ & $334(9 \cdot 35)$ & $4 \cdot 4(5.95)$ & $67(12 \cdot 5)$ \\
\hline Ser & $7010(6.98)$ & $379(7.92)$ & $(12 \cdot 7)$ & $46 \cdot 4(6.62)$ & $308(8 \cdot 60)$ & $4.9(6.63)$ & $30(5 \cdot 58)$ \\
\hline Glu/Gln & $11200(11 \cdot 1)$ & $343(7 \cdot 16)$ & $(7 \cdot 18)$ & $49 \cdot 1(7 \cdot 54)$ & $261(7 \cdot 29)$ & $6 \cdot 2(8 \cdot 38)$ & $45(8 \cdot 37)$ \\
\hline Pro & $4200(4 \cdot 18)$ & $465(9 \cdot 15)$ & $(7 \cdot 51)$ & $48 \cdot 6(7 \cdot 18)$ & $312(8 \cdot 71)$ & $5 \cdot 3(7 \cdot 17)$ & $14(2 \cdot 61)$ \\
\hline Gly & $8560(8.53)$ & $439(9 \cdot 32)$ & $(8 \cdot 78)$ & $77 \cdot 1(11 \cdot 2)$ & $377(10 \cdot 5)$ & $8 \cdot 2(11 \cdot 1)$ & $55(10 \cdot 3)$ \\
\hline $\mathrm{Ala}$ & $6730(6.70)$ & $232(4 \cdot 81)$ & $(5 \cdot 36)$ & $49 \cdot 8(6 \cdot 31)$ & $206(5 \cdot 76)$ & $2 \cdot 8(3.92)$ & $26(4 \cdot 83)$ \\
\hline Val & $5200(5 \cdot 18)$ & $224(4 \cdot 67)$ & $(4 \cdot 72)$ & $26 \cdot 9(4 \cdot 45)$ & $151(4 \cdot 21)$ & $3 \cdot 4(4 \cdot 60)$ & $24(4 \cdot 46)$ \\
\hline Ile & $4750(4 \cdot 73)$ & $157(3 \cdot 29)$ & $(3 \cdot 20)$ & $26 \cdot 7(4 \cdot 73)$ & $109(3 \cdot 04)$ & $2 \cdot 0(2 \cdot 70)$ & $29(5.39)$ \\
\hline Leu & $6200(6 \cdot 17)$ & $151(3 \cdot 15)$ & $(2 \cdot 46)$ & $29 \cdot 2(4 \cdot 60)$ & $111(3 \cdot 10)$ & $2.8(3.92)$ & $31(5 \cdot 77)$ \\
\hline Tyr & $2520(2 \cdot 51)$ & $145(3.03)$ & $(2 \cdot 16)$ & $14.7(3.51)$ & $84.5(2 \cdot 36)$ & $1.5(2.02)$ & $19(3 \cdot 54)$ \\
\hline Phe & $3270(3.26)$ & $116(2 \cdot 44)$ & $(1.79)$ & $15 \cdot 0(2 \cdot 68)$ & $48 \cdot 9(1 \cdot 37)$ & $1.8(2.43)$ & $18(3 \cdot 35)$ \\
\hline His & $1860(1 \cdot 85)$ & $213(4 \cdot 44)$ & $(3 \cdot 61)$ & $23 \cdot 2(3 \cdot 25)$ & $185(4 \cdot 27)$ & $3.0(4 \cdot 06)$ & $14(2 \cdot 61)$ \\
\hline Lys & $7210(7 \cdot 18)$ & $227(4 \cdot 74)$ & $(5 \cdot 10)$ & $17 \cdot 6(3 \cdot 28)$ & $138(3 \cdot 86)$ & $3.0(4.06)$ & $18(3 \cdot 35)$ \\
\hline Arg & $3690(3.67)$ & $212(4 \cdot 42)$ & $(3.89)$ & $32 \cdot 3(4 \cdot 87)$ & $147(4 \cdot 11)$ & $9 \cdot 0(12 \cdot 1)$ & $23(4 \cdot 28)$ \\
\hline Cys & - & - & $(10 \cdot 3)$ & - & - & - & - \\
\hline Met & - & - & $(0 \cdot 41)$ & - & - & - & - \\
\hline $\operatorname{Trp}$ & - & - & $(1 \cdot 00)$ & - & - & - & - \\
\hline Subtotal & 88600 & 4220 & & 577 & 3190 & 65 & 410 \\
\hline Total\$ & 100000 & 4770 & & 652 & 3610 & 74 & 540 \\
\hline
\end{tabular}

, Not determined.

* Mean of two independent determinations, which differed by $<20 \%$. A unit represents one spore, spore coat or extracted spore coat. The percentage of total amino acids in the sample is shown in parentheses; all samples are assumed to contain $11.7 \%$ Cys, Met and Trp, which is the summed level of these residues in five known coat proteins (see footnote $\ddagger$ ).

$\dagger$ Spore coats were purified to homogeneity after germination. Coats were extracted with urea, and the extract was separated from the residue, which was then re-extracted with SDS.

$\ddagger$ Values calculated from the deduced amino acid sequences, minus the signal peptide, of five outer layer spore coat proteins, SP96, SP87, SP75, SP70 and SP60.

$\int$ The total values for coats and extracts were calculated by subtotalling the measured amino acid levels, and then multiplying by a factor of $1 \cdot 13$, to correct for the values of Cys, Met and Trp, which could not be determined by the method, assuming that theit proportions ate the same as in the five coat proteins listed in footnote $\neq$. A correction was made in the same way for the missing value for Asp/Asn of the SDS extract.

spore coat $[4.77 \mathrm{fmol}$ amino acid per coat (Table 2, column 3 , bottom row) $\times 109$ average fg amino acid per fmol], compared to $0.58 \mathrm{pg}$ per coat as determined by a Coomassie Blue dye-binding method (Aparicio et al., 1990). The spore coat comprises $5 \%$ of the total spore protein (Table 2, columns 3 and 2).

To determine how protein is attached to the coat, the coat preparation was extracted with protein denaturants and MSH. Hot urea/MSH released $85 \%$ of the total coat protein (Table 2, column 6), and re-extraction of the insoluble residue with hot SDS/MSH solubilized $88 \%$ of the remaining protein (Table 2 , column 8 ). Thus, little protein is irreversibly cross-linked, and proteins can be identified, quantified and characterized by conventional biochemical methods. While these results do not rule out the possibility that proteins are extracted as multimers, it is unlikely that such multimers would be very large because $>90 \%$ of all protein enters the running gel during SDS-PAGE (data not shown; Gonzalez-Yanes $e t$ al., 1989).

\section{Most coat proteins are disulfide cross-linked}

Previous studies have reported that extraction of most coat proteins requires reducing agents, which could be explained if proteins were cross-linked by disulfide bonds (Wilkinson \& Hames, 1983). One protein, SP96 (previously termed $\mathrm{p} 112$ ), does not require reducing agents for extraction. However, in our experience, a variable percentage of most proteins are extracted from both 1-dold and 7-d-old spores without reducing agents (Aparicio et al., 1990). This indicates that there is heterogeneity in the nature of the association of individual copies of the same protein species with the coat, or that disulfide bonds 


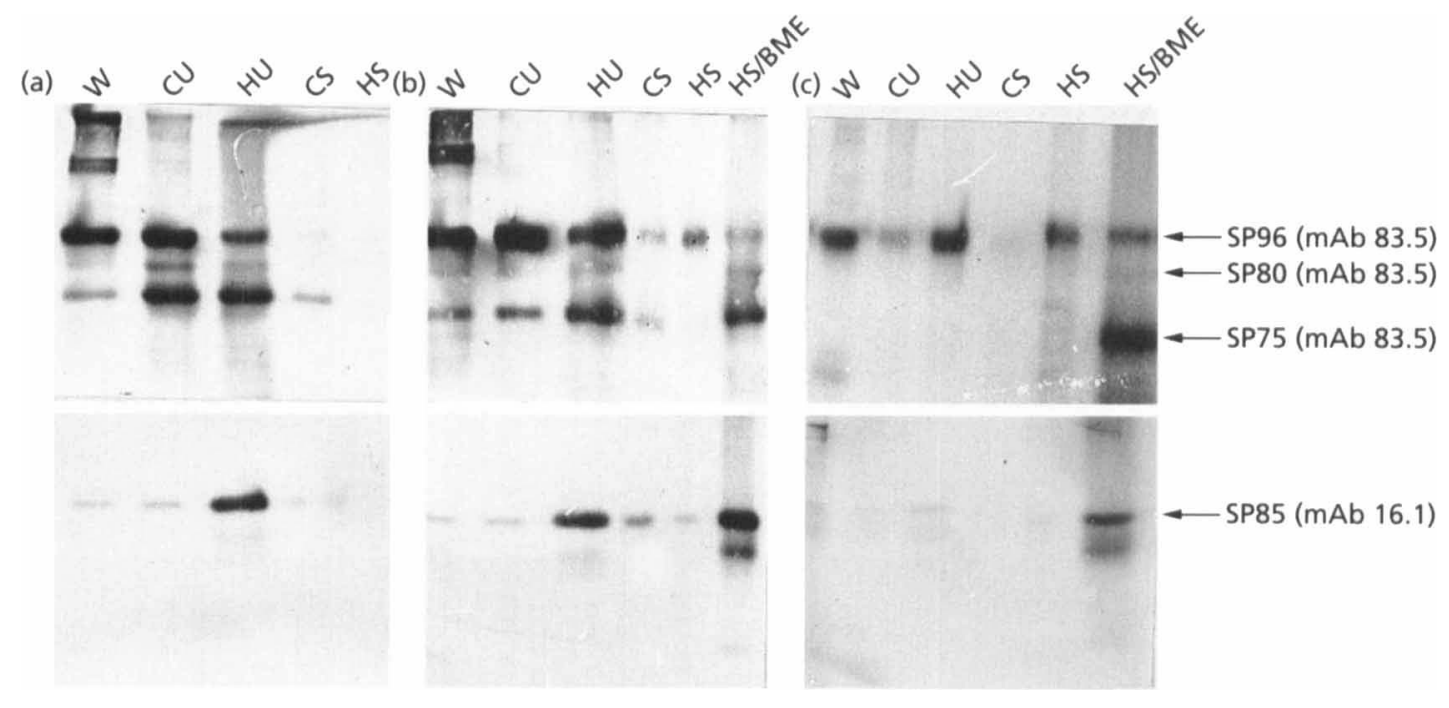

Fig. 1. Sequential extraction of proteins from spore coats. To determine how proteins were associated with the coat 1-day-old spores were divided into three groups, and each was sequentially extracted and centrifuged from water at $22{ }^{\circ} \mathrm{C}(\mathrm{W}) ; 8 \mathrm{M}$ urea at $22{ }^{\circ} \mathrm{C}(\mathrm{CU}) ; 8 \mathrm{M}$ urea at $100{ }^{\circ} \mathrm{C}(\mathrm{HU}) ; 2 \%$ SDS at $22{ }^{\circ} \mathrm{C}(\mathrm{CS}) ; 2 \%$ SDS at $100{ }^{\circ} \mathrm{C}(\mathrm{HS}) ;$ and $2 \%$ SDS $/ 5 \%$ $\mathrm{MSH}$ at $100^{\circ} \mathrm{C}(\mathrm{BME})$. The extracting solutions contained $5 \% \mathrm{MSH}$ (a) or no reducing agent (control) (b). The spores of the third group were pretreated with $100 \mathrm{mM}$ IAA to alkylate free thiol moieties, and no reducing agent was present until the final step (c). The supernatants from each centrifugation were collected and volumes derived from $3 \times 10^{5}$ original spores were analysed by SDS-PAGE, blotting and immunoprobing with the indicated antibodies.

may simply stabilize conformations which support noncovalent interactions that are resistant to denaturation. However, the data are ambiguous because protein denaturants used to extract spore coat proteins have the potential, if reduced cysteine is present, to promote disulfide exchange reactions (Creighton et al., 1995). Even in the absence of a reducing agent, this could result in the release of proteins from disulfide bonds which normally tether them to the coat.

To address this issue, free thiol groups of the spore coat were first alkylated using iodoacetamide to block thiol migration. To evaluate the effect of prealkylation, three separate experimental series of spores were sequentially extracted with water, urea, hot urea, SDS and hot SDS. The solutions of the first series contained $5 \% \mathrm{MSH}$. The second (control) series contained no reducing agent. Spores of the third series were pretreated with IAA and contained no reducing agent. The behaviour of the five proteins monitored fell into two categories.

SP96, the sole member of the first category, elutes partially in the water wash and is completely eluted by hot urea in the control series (Fig. 1). The elution of this protein is not affected by prior alkylation or the presence of MSH. Thus, some SP96 resides in the interspore matrix and disulfide bonds are not relevant to the association of SP96 with the spore coat matrix.

The second category includes the remaining proteins examined (Fig. 1). In the control series, these proteins were partially eluted in the hot urea step, but required hot SDS/MSH for complete extraction, as previously observed (Aparacio et al., 1990). When prealkylated with
IAA, however, little or no detectable SP75, SP80 or SP85 was extracted without reducing agent. In the presence of reducing agent, essentially all protein extracted in either the $22^{\circ} \mathrm{C}$ or the hot urea step. Indistinguishable results were obtained for SP87 probed with anti-PL3, SP86 probed with $\mathrm{mAb} 5.1$, SP70 probed with anti-SP70 (2H3) and SP60 determined by Coomassie Blue staining (data not shown). Inclusion of $10 \mathrm{mM}$ EDTA in the solutions had no effect on the results for both categories of proteins (data not shown), suggesting that divalent cations are not critical for retaining proteins in the coat. Similar results were found with both 1- and 7-d-old spores (data not shown). Since prior alkylation blocked elution of protein under denaturing conditions, it is likely that the disulfide bonds affected by reduction are direct intermolecular cross-links, rather than intramolecular bonds that stabilize a conformation necessary for denaturant-sensitive intermolecular contacts. Thus, all copies of these protein species are cross-linked in a disulfide-dependent fashion. Since polysaccharides do not participate in disulfide crosslinks, protein appears to form a matrix continuum which, once formed, is independent of the cellulose system of fibrils. This arrangement is reminiscent of the epithelial basement membrane, in which laminin and collagen type IV separately self- and inter-associate to form the final fabric of the matrix (Yurchenko et al., 1992).

\section{Identification of coat proteins by two-dimensional gel electrophoresis}

To determine the total number of coat proteins, twodimensional gel electrophoresis was employed to extend earlier one-dimensional gel analyses of the coat (Devine $e t$ 

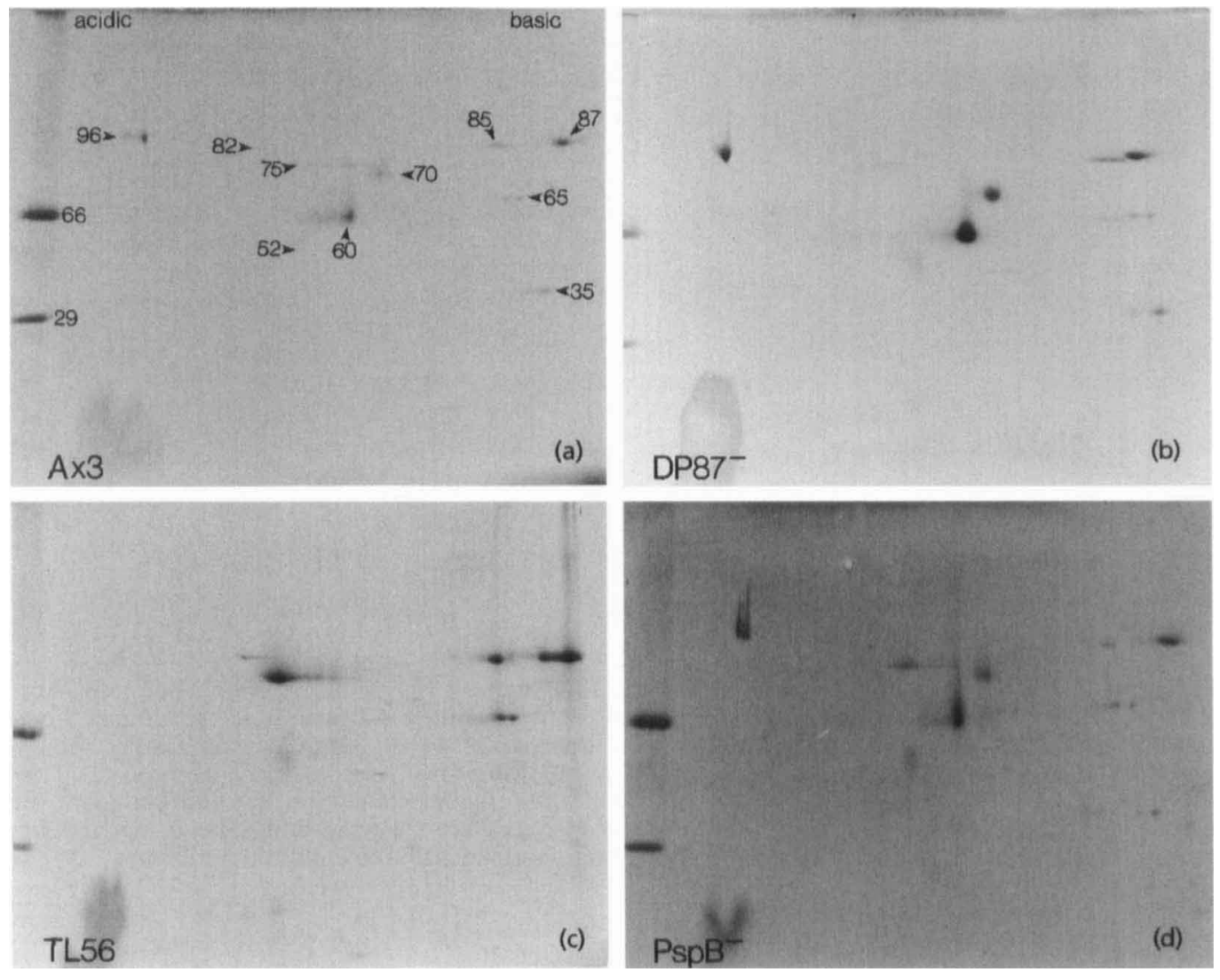

Fig. 2. Two-dimensional gel electrophoresis of spore coat proteins from normal and gene-disruption strains. Coats were highly purified from strains Ax3 (a), DP87-(b), TL56 (c) and PspB- (d) and solubilized in urea/SDS/MSH. Coats $\left(2 \times 10^{7}\right)$ were loaded at the basic end of standard O'Farrell two-dimensional polyacrylamide gels which were subsequently stained with Coomassie Brilliant Blue. $M_{r}$ markers were applied at the acidic end of the second dimension gels. The nine most abundant and one minor-abundance proteins are labelled, and are listed with their apparent $M_{\mathrm{r}}$ and pl values in Table 3 .

al., 1982; Wilkinson \& Hames, 1983; Akalehiywot \& Siu, 1983; Gonzalez-Yanes et al., 1989). Since all protein can be extracted from the coat, this approach was expected to identify all proteins because of its ability to resolve those proteins with similar $M_{\mathrm{r}}$ values. Known coat proteins were identified based on previous one- and two-dimensional separations (Devine et al., 1982, 1983; West \& Loomis, 1985), immunoprobing of Western blots from parallel gels with $\mathrm{mAbs}$ and absence of proteins in coats from gene deletion strains.

Nine major protein species are visualized in normal strain Ax3 spore coats after staining with Coomassie Blue (Fig. 2a). The same proteins are also found in another strain, $\mathrm{PspB}^{-}$(Powell-Coffman \& Firtel, 1994), which is derived from strain JH010 and lacks the $p s p B$ gene (Fig. 2d). The positions of SP96 and SP75 were determined on immunoblots from parallel gels using mAb 83.5 (Fig. 3b), confirming previous reports (Devine et al., 1982; West \& Loomis, 1985). The position of SP70 was determined using the anti-SP70 (2H3) antiserum (data not shown), as previously described (Gonzalez-Yanes et al., 1989). SP60 was identified on the basis of its characteristic migration compared to previous two-dimensional gel analysis (Devine et al., 1982). The identities of SP96, SP70 and SP60 were confirmed by their absence in the triple gene deletion strain TL56 (Fosnaugh et al., 1995) (Fig. 2c). SP87, encoded by the $p s p D$ (PL3) gene (Yoder et al., 1994), was identified using anti-PL3 antibody (Fig. 3a). SP85 was identified using mAb 16.1 (Fig. 3a), and is equivalent to the PsB protein recognized by $\mathrm{mAb}$ MUD102 (Watson $e t$ al., 1994). Three previously unrecognized proteins are SP52, which migrates broadly, and SP65 and SP35, which migrate as isoelectric stutters near the basic end of the gel.

The lower than predicted isoelectric points of SP96 and SP75 (Table 3), based on the algorithm of Skoog \& Wichman (Hitachi MacDNAsis Pro 3.0 software) applied to their amino acid sequences, can be explained by phosphorylation of their Ser residues (Akalehiywot \& Siu, 1983; Devine et al., 1982; West \& Erdos, 1990). The higher than predicted isoelectric points of SP87, SP70 and SP60 are possibly the result of re-formation during focussing of intramolecular disulfide bonds (see below), which the algorithm assumes do not exist. The higher than predicted $M_{\mathrm{r}}$ values for these proteins, based on their amino acid sequences (see Table 3), can be explained by their phosphorylation and glycosylation (Riley et al., 1993; West \& Erdos, 1990), and the presence of oligo Ser/Thr tracts. 


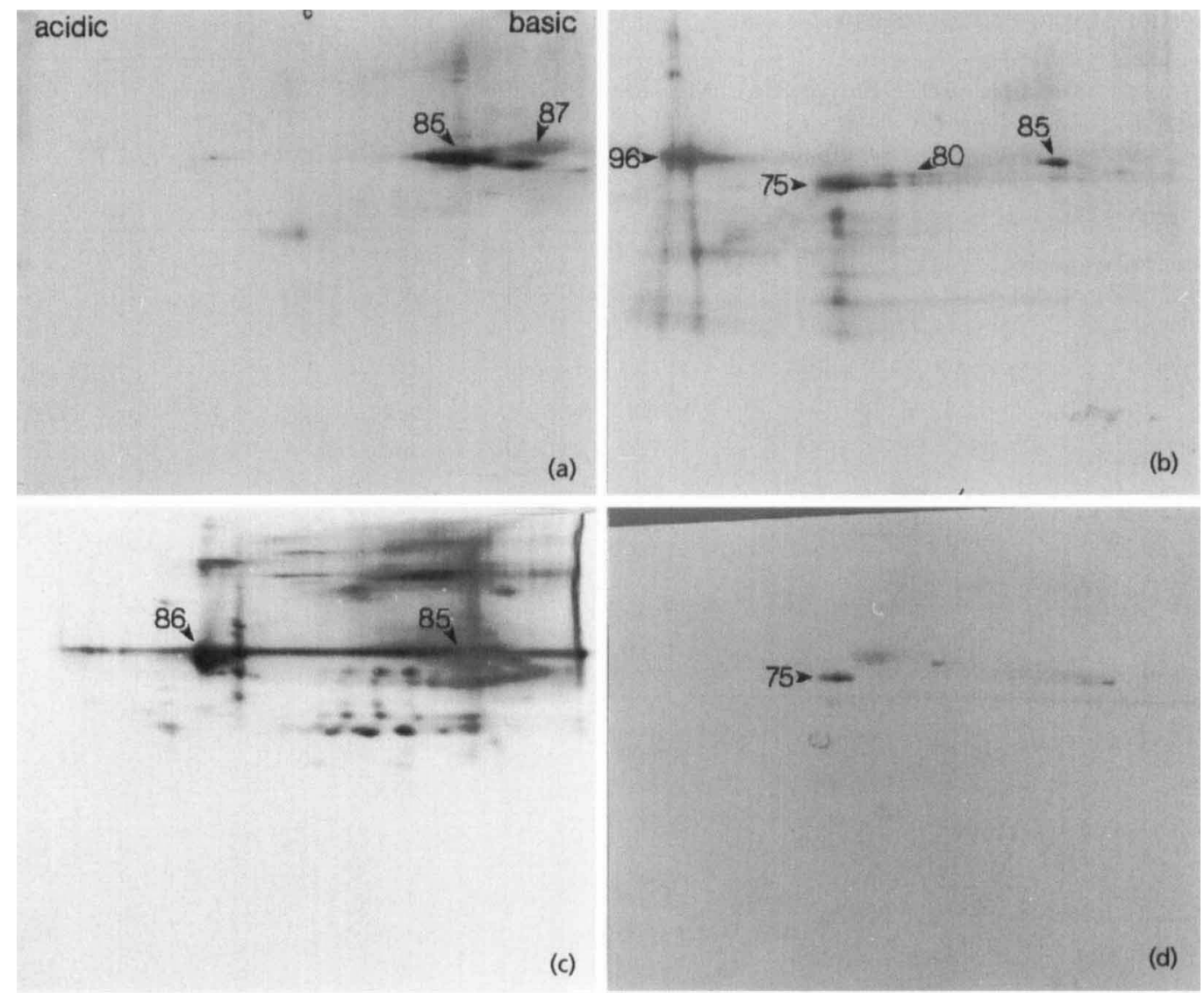

Fig. 3. Identification of coat proteins by immunoblotting. Strain Ax3 spore coats $\left(1 \times 10^{6}\right)$ were subjected to twodimensional electrophoresis, as described in Fig. 2 and Western blotting prior to immunoprobing. (a) Blot double-probed with $\mathrm{mAb} 16.1$ and anti-PL3 antiserum showing the positions of SP85 and SP87, respectively. The minor labelling of SP60 by anti-PL 3 was reproducible and probably reflects protein structural homologies. The binding of mAb 16.1 to a minor species below SP87 was also reproducible. (b) Blot double-probed with mAbs 83.5 and 16.1 showing the positions of SP96 and SP75, and SP85, respectively, in addition to numerous minor species labelled by mAb 83.5 which were reproducibly detected when the blot was overdeveloped. (c) Blot probed with mAb 5.1 showing the position of SP85, the major reactive species near the basic end, and SP86, the major reactive species toward the acidic end. This blot was overdeveloped to reveal the numerous other minor-abundance species present in this preparation which reacted with this antibody. (d) Blot probed with anti-DP87 showing a protein in the same position as SP75, which was confirmed by secondary probing with mAb83.5 (not shown). The minor labelling of other proteins with this antibody was reproducible, consistent with sequence homologies among coat proteins.

The same nine major-abundance proteins are visualized in overloaded gels stained with Coomassie Blue (Fig. 4a). Silver staining (Fig. 4b) reveals most of the majorabundance species as either positive or negative images, though SP70 and SP85 are not identified by this technique. The high apparent abundance of SP52 is emphasized by silver staining. In general, it is difficult to compare the relative abundance of the major protein species, because of variation in either stainability or sharpness of migration during focussing and electrophoresis.

These gels also indicate reproducibly the existence of several minor proteins, including SP82, SP80, SP64, SP63 and SP51 (Figs 4a, b; Table 3). In addition, silver staining reveals a number of poorly resolved basic species over a wide range of $M_{\mathrm{r}}$ values (Fig. 4b), which do not stain with Coomassie Blue and warrant further attention. The previously described SP86 (West \& Erdos, 1992) is recognized by $\mathrm{mAb} 5.1$. $\mathrm{mAb} 5.1$ reacts with two major species on two-dimensional gels with the same apparent $M_{\mathrm{r}}$ (Fig. 3c). The more basic major species is SP85, recognized by $m A b 16.1$; the more acidic species, with an unusual blob-like image, is probably SP86, apparently present in low abundance because it is not detected by protein stains (Figs 4a, b). SP86 is polymorphic on oneand two-dimensional gels, displaying a larger apparent $M_{\mathrm{r}}$ in WS576 (unpublished data), a strain in which SP85 was previously shown to have a reduced $M_{\mathrm{r}}$ value (Watson et al., 1994).

In conclusion, the $D$. discoideum spore coat consists of a finite number of major-abundance species, and additional minor species, some of which are likely to be important for coat structure and function. Genes for most of the 
Table 3. Properties of spore coat proteins

\begin{tabular}{|c|c|c|c|c|c|c|c|}
\hline $\begin{array}{l}\text { Protein } \\
\text { name/gene/ } \\
\text { linkage group }\end{array}$ & $\begin{array}{l}\text { Residues after } \\
\text { signal peptide } \\
\text { cleavage }\end{array}$ & $\begin{array}{c}\text { Polypetide } \\
M_{\mathrm{r}} \text { after } \\
\text { signal } \\
\text { cleavage } \ddagger\end{array}$ & $\begin{array}{c}\text { Measured } \\
M_{t} \downarrow\end{array}$ & $\begin{array}{l}\text { Predicted } \\
\quad \text { pI } \|\end{array}$ & $\begin{array}{c}\text { Measured } \\
\text { pIg }\end{array}$ & $\begin{array}{l}\text { Phosphoryl- } \\
\text { ation** }\end{array}$ & $\begin{array}{l}\text { Glycosyl- } \\
\text { ationtt }\end{array}$ \\
\hline \multicolumn{8}{|c|}{ Major abundance species } \\
\hline $\mathrm{SP} 96 / \cot A / 2$ & $* 21-600$ & 57507 & 96000 & $5 \cdot 34$ & $4 \cdot 3$ & yes & $\begin{array}{l}O(\mathrm{GA}-\mathrm{X}) \\
1 \text { poss. } N \ddagger \ddagger\end{array}$ \\
\hline $\mathrm{SP} 87 / p s p D / 2$ & $* 22-678$ & 69351 & 87000 & 6.9 & $7 \cdot 6$ & & 1 poss. $N \ddagger \ddagger$ \\
\hline SP85 & & & 85000 & & 6.85 & & $O(\mathrm{GA}-\mathrm{XI})$ \\
\hline $\begin{array}{l}\mathrm{SP} 75 /(\mathrm{DP} 87) \\
\cot D / 4\end{array}$ & $\nmid 23-555$ & 56143 & 75000 & $7 \cdot 29$ & $5 \cdot 2$ & yes & $\begin{array}{l}1-3 \mathrm{NSS} \\
O(\mathrm{GA}-\mathrm{X})\end{array}$ \\
\hline $\mathrm{SP} 70 / \cot B / 2$ & $+21-537$ & 54505 & 70000 & $4 \cdot 69$ & $5 \cdot 7-5 \cdot 8$ & no & $1 N S S$ \\
\hline SP65 & & & 65000 & & $7 \cdot 0-7 \cdot 2$ & & \\
\hline $\mathrm{SP} 60 / \cot C / 2$ & $\dagger 24-424$ & 46927 & 60000 & $4 \cdot 67$ & 5.6 & no & no \\
\hline $\begin{array}{l}\text { SP52 } \\
\text { SP35 }\end{array}$ & & & $\begin{array}{l}52000 \\
35000\end{array}$ & & $\begin{array}{c}5 \cdot 3 \\
6 \cdot 5-7 \cdot 5\end{array}$ & & \\
\hline \multicolumn{8}{|c|}{ Minor abundance species } \\
\hline SP86 & & & 85000 & & $4 \cdot 8$ & & $O(\mathrm{GA}-\mathrm{XX})$ \\
\hline SP82 & & & 82000 & & $5 \cdot 15$ & & \\
\hline SP80 & & & 80000 & & & yes & $\begin{array}{l}O(\mathrm{GA}-\mathrm{X}) \\
O(\mathrm{GA}-\mathrm{XX})\end{array}$ \\
\hline SP64 & & & 64000 & & $6.7-6.8$ & & \\
\hline SP63 & & & 63000 & & $5 \cdot 7-6 \cdot 1$ & & \\
\hline SP51 & & & 51000 & & $5 \cdot 9$ & & \\
\hline
\end{tabular}

* First amino acid deduced from consensus signal peptidase recognition site (von Heijne, 1985).

†First amino acid determined by Edman degradation (Fosnaugh \& Loomis, 1989b; Table 4).

$\ddagger$ Calculated.

$\int$ Taken from previous reports of SDS-PAGE determinations (see text), except for SP82, SP65, SP64, SP63, SP52, SP51 and SP35, which are from this study.

|| Based on algorithm of Skoog \& Wichman, as calculated by MacDNAsis Pro 3.0.

9 Determined by two-dimensional electrophoresis (Figs 2-4).

** Determined by metabolic labelling with ${ }^{32} \mathrm{PO}_{4}^{3-}$; a blank indicates not known (Akalehiywot \& Siu, 1983; Devine et al., 1982; West \& Erdos, 1990).

†† $O$-glycosylation determined by a combination of reaction with $\mathrm{mAbs}$ (designated as GA) and analysis of products of $\beta$-elimination (West \& Erdos, 1990; Riley et al., 1993).

$\ddagger \ddagger$ Derived amino acid sequence contains the indicated number of $N$-glycosylation sequons.

$\iint$ Determined by $M_{\mathrm{r}}$ shift in a mod $A$ ( $\boldsymbol{\alpha}$-glucosidase- $2^{-}$) mutant strain, M31 (C. M. West, unpublished data).

major species have been cloned, and inspection of the deduced amino acid sequences indicates the functional roles described below.

\section{Coats and interspore matrix derive from a common extracellular space but are distinct}

Superficial to the spore coat, in the interstices between spores, resides the interspore matrix fluid. Since several coat proteins have been detected in the interspore matrix (West \& Erdos, 1988, 1990, 1992; Watson et al., 1994; Nakao et al., 1994), the protein composition of the matrix was examined to address whether what is considered a coat protein is in fact a contaminant from the interspore matrix. The protein content of the interspore matrix, collected as a water wash from sori of strains $\mathrm{Ax} 3, \mathrm{X} 22$ or NC-4, grown either axenically or on $K$. aerogenes, was measured using a Coomassie Blue dye-binding assay. The values, ranging from $250-650 \mathrm{fg}$ per spore, are similar to those for the protein content of the spore coat, $520 \mathrm{fg}$ per coat, though a spore equivalent of interspore matrix occupies a much larger volume than the spore coat. To compare the overall protein composition of coats and matrix, a quantity of interspore matrix equivalent to the number of spore coats displayed in Fig. 4b is shown in Fig. 4c. Silver staining reveals numerous protein species over a wide range of apparent isoelectric points and $M_{\mathrm{r}}$ values. Known spore coat proteins are not abundant enough to be correlated with individual protein species with confidence, with the exception of SP96. As shown 

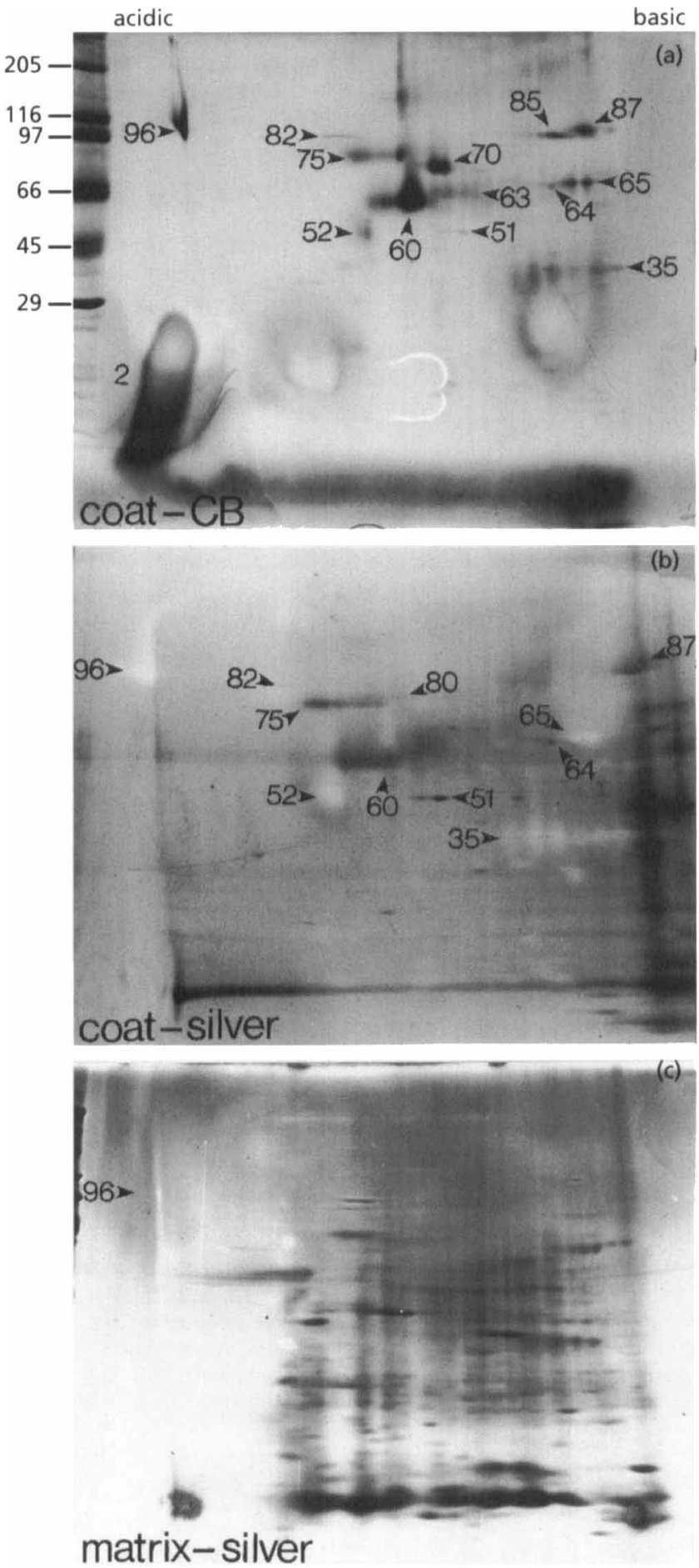

Fig. 4. Comparison of spore coat and interspore matrix proteins. Highly purified coats and interspore matrix, i.e. the water wash fraction from sori, were isolated from strain $A \times 3$ and subjected to two-dimensional gel electrophoresis as in Fig. 2. (a) $1 \times 10^{8}$ coats, gel stained with Coomassie Brilliant Blue; (b) $2 \times 10^{7}$ coats, gel stained with a silver method; (c) interspore matrix from $2 \times 10^{7}$ spores, gel stained with Coomassie Brilliant Blue followed by staining with a silver method. Both abundant and minor coat proteins are labelled in (a) and (b); the apparent $M_{\mathrm{r}}$ and $\mathrm{pl}$ of each protein are listed in Table 3 . The stuttered spots referred to as SP35 and SP65, which varied in their apparent isoelectric points, are assumed to represent single gene products.
Table 4. Amino acid sequence of purified SP75 and endoproteinase Lys-C-derived cleavage products

\begin{tabular}{|ll|}
\hline Treatment & \multicolumn{1}{c|}{ Sequence* } \\
\hline None & WGGGRDXE \\
Endoproteinase Lys-C & $\{\mathrm{K}\}$ xxRTGEIFEIW'S \\
Endoproteinase Lys-C & $\{\mathrm{K}\}$ xxxxxxRPPPRPPVDQCRNQ \\
Endoproteinase Lys-C & $\{$ K $\}$ NTRTGEIFEIxSxxKPHxDFVPYH \\
Endoproteinase Lys-C & $\{$ K $\}$ KEFFxVNRDxxxxxD \\
\hline
\end{tabular}

* Letters denote standard single letter abbreviations for amino acids; $x=$ not determined; $\{K\}$ denotes a Lys residue predicted on the basis of specificity of endoproteinase Lys-C, which cleaves on the $\mathrm{C}$-terminal side of this residue. All sequences match translations of the published cDNA sequence for the DP87 gene (Ozaki et al., 1993).

above (Fig. 1) and elsewhere (West \& Erdos, 1990, 1992; Yoder et al., 1994), only a minor proportion of the coat proteins SP87, SP86, SP85, SP75, SP70 and SP60 resides in the interspore matrix. Furthermore, the level of coat proteins detected in the interspore matrix varies substantially between strains (Zhang \& West, unpublished data). Some matrix proteins are lysosomal enzymes (Seshadri et al., 1986; Lenhard et al., 1989), and probing immunoblots with an anti-discoidin antibody (Erdos \& Whitaker, 1983) indicates that one corresponds to the lectin discoidin; discoidin is not detected in the coat (data not shown). Coat proteins represent a variable, minor fraction of the overall composition of the interspore matrix, suggesting that the specificity of intermolecular associations ensures that matrix and coat proteins are largely unique.

\section{Identification of the coat protein SP75 as the product of the DP87 gene}

To gain additional information about the major coat protein SP75, this protein was extracted from spores in $8 \mathrm{M}$ urea/MSH, and purified to homogeneity using DEAE ion exchange chromatography and SDS-PAGE (see Methods). Purified SP75 was digested with endoproteinase Lys-C, and both intact and digested protein were subjected to Edman degradation after SDS-PAGE and immunoblotting. The sequences obtained (Table 4) belong to the previously characterized DP87 gene (Ozaki et al., 1993). The sequence of the intact protein identifies the site of signal peptide cleavage after $\mathrm{Gly}_{22}$, which conforms with consensus signal peptidase cleavage sites (von Heijne, 1985).

Consistent with the sequence data, coats from a gene disruption strain DP87- lacked a protein at the position of SP75 (Fig. 2b). Both SP75 and the DP87 protein are missing from these coats as determined by labelling immunoblots with $\mathrm{mAb} 83.5$ or anti-DP87, respectively (data not shown). No other abundant proteins or SP86 (data not shown) are missing. Furthermore, anti-DP87 labels a protein at the position of SP75 in immunoblots of normal spore coats (Fig. 3d). The weaker labelling of 

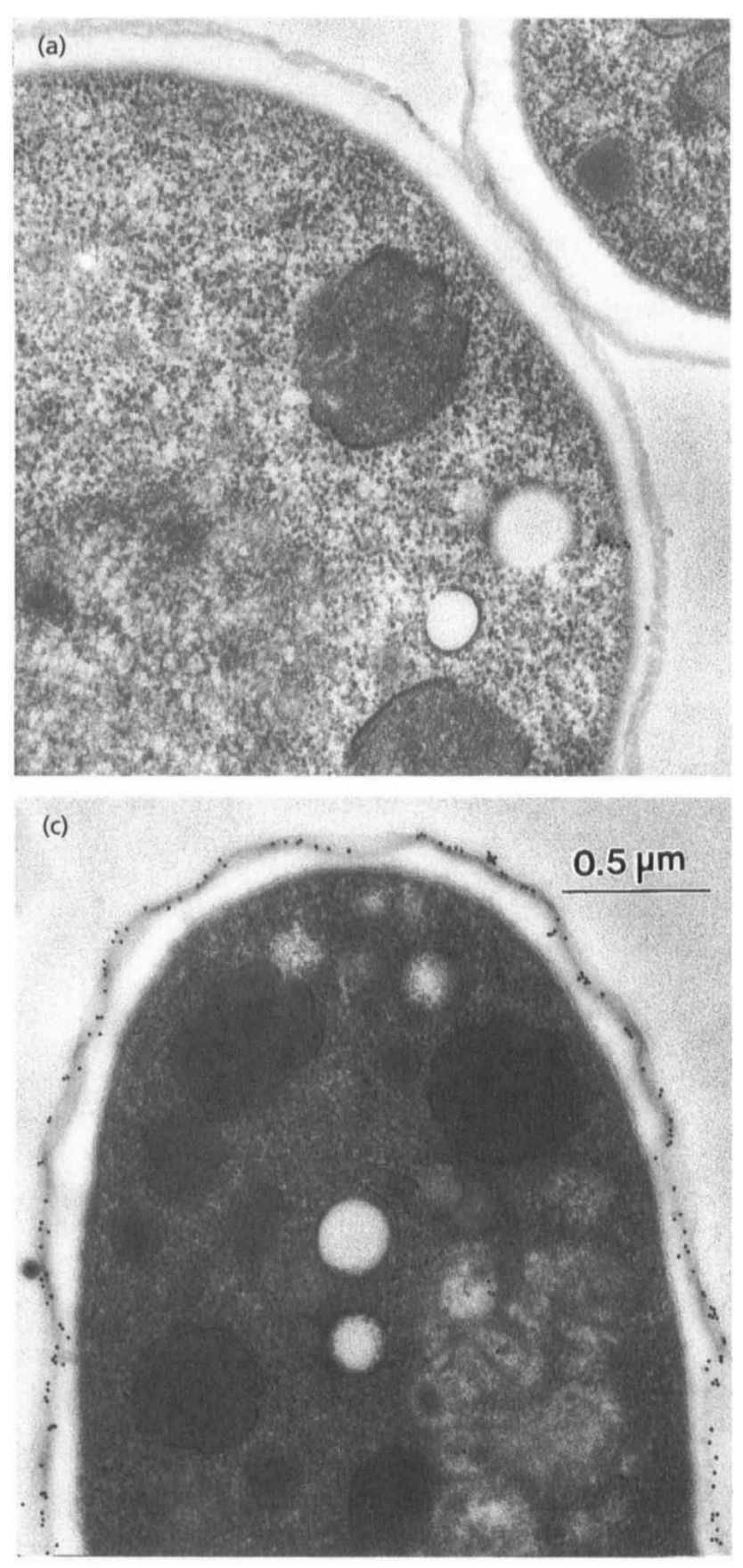

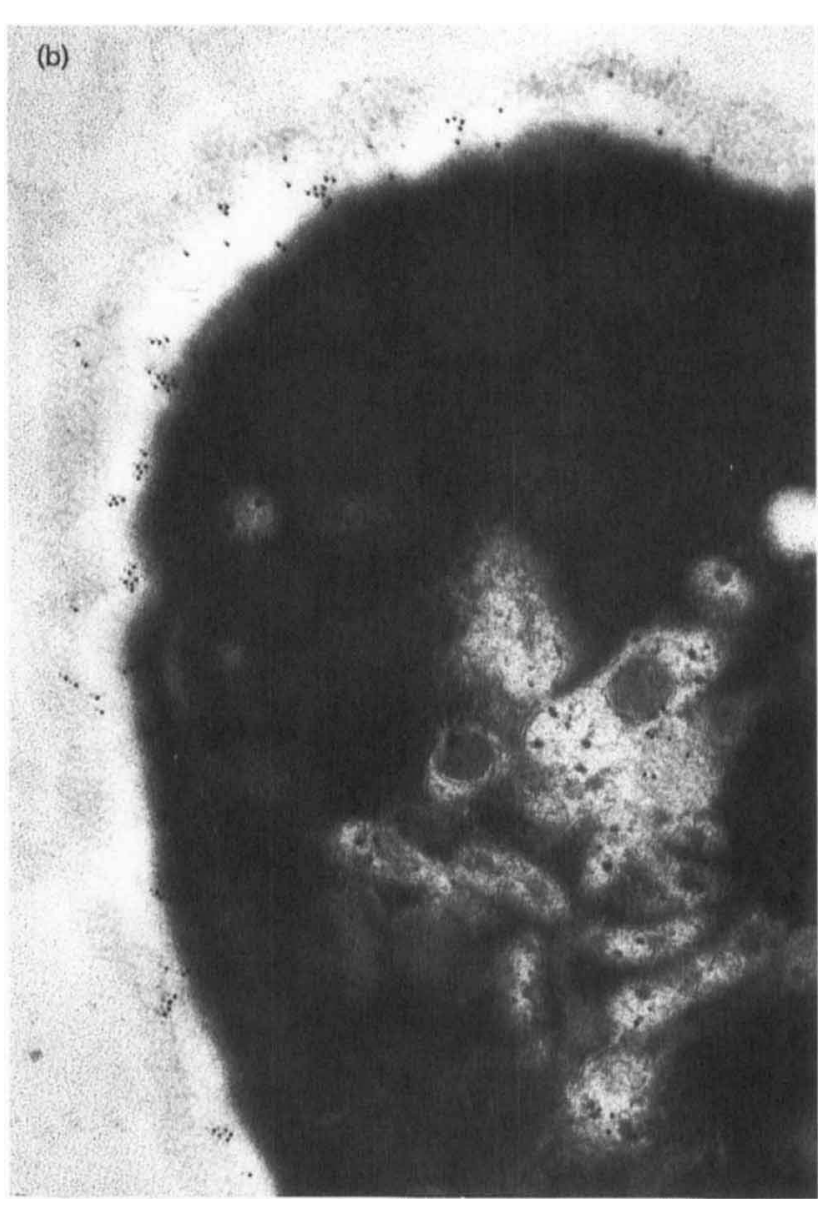

Fig. 5. Electron microscopic immunolocalization of SP75. Thin sections from spores of strains Ax3 and TL56 were immunoprobed with anti-DP87 antibody and mAb 83.5, using an indirect colloidal gold technique. (a) Strain $A \times 3$ spores probed with anti-DP87; (b) strain TL56 spores probed with anti-DP87; (c) strain TL56 spores probed with mAb 83.5. other spots, which also occurs with the anti-SP87 (PL3) antibody (Fig. 3a and data not shown), is probably because these proteins share related sequences (see below) which cross-react with these anti-polypeptide rabbit antisera. Finally, DP87- ${ }^{-}$spore coats exhibit a reduced buoyant density (Table 1), consistent with a chemical difference in their composition.

In contrast to the biochemical data, anti-DP87 fails to label coats in thin sections (Nakao et al., 1994; Fig. 5a). This raises the possibility that critical epitopes required by the anti-DP87 antibody are masked in the coat but not in the interspore matrix, where this protein was previously localized (Nakao et al., 1994). To circumvent this possibility, spores from strain TL56, which lacks three coat proteins but retains SP75 and is more permeable to macromolecules (Fosnaugh et al., 1995), were examined. Immunogold antibody conjugates localized exclusively in the coat in these washed spores (Fig. 5b). Gold particles tended to associate with the inner and middle layers of the coat, whereas the fucose epitope (GA-X) localized in the outer layer of both mutant and normal coats as determined using $\mathrm{mAb} 83.5$ (Fig. 5c), indicating that this aspect of organization of the coat is not affected by the absence of the coat proteins SP96, SP70 and SP60. Since SP75 is the major coat protein expressing the fucose epitope in this 
strain, separate epitopes of SP75 may reside in the inner and outer layers of the coat, straddling the cellulosic middle layer.

In summary, a coat location for SP75 is supported by physical, genetic, biochemical and microscopic evidence. The high level of SP75 expression previously observed in the interspore matrix (Nakao et al., 1994) does not occur in strain Ax3, but we have observed that the level of coat proteins in this compartment varies among cell strains ( $Y$. Zhang \& C. M. West, unpublished data).

\section{Effects of coat gene deletions on spore coat assembly}

The substantial molecular deficiencies of the gene disruption strain TL56, which lacks SP96, SP70 and SP60 (Fosnaugh et al., 1995), and DP87- (Tasaka et al., 1990), which lacks SP75, are confirmed by the results shown in Figs 2(b-c). Coats are still formed by these strains, though they exhibit reduced buoyant densities (Table 1), and strain TL56 also has a relatively high germination efficiency after temperature activation (Table 1). Examination of a series of deletion strains elegantly showed that the contributions of SP96, SP70 and SP60 to the macromolecular impermeability of the coat are additive (Fosnaugh et al., 1995). It is striking that the remaining major-abundance coat proteins (Figs 2b, c) and SP86 (data not shown) are incorporated normally in TL56 and DP87 ${ }^{-}$, and that the fucose epitope is localized correctly in TL56 (Fig. 5c), despite the absence of major proteins. The one exception is that SP35 is missing from strain TL56 coats, indicating that this protein is normally retained in the coat by association with one of the missing proteins. Thus, with the possible exception of SP35, the phenotypic consequences can be ascribed to the specific proteins deleted. These observations argue against a crystalline model for protein organization in the coat, or any other model in which incorporation of proteins is strictly dependent upon associations with SP96, SP75, SP70 or SP60. An alternative indeterminate model of outer-layer-associated protein packing is supported by predicted characteristics of these proteins inferred from analysis of their sequences (see below).

\section{DISCUSSION}

\section{The proteins of the spore coat}

The germinated spore coat has a protein content slightly greater than its total carbohydrate content, including cellulose (West et al., unpublished results), having an equivalent of about $5 \times 10^{6}$ protein molecules with an average polypeptide $M_{\mathrm{r}}$ of $60000\left[\left(5.2 \times 10^{-13} \mathrm{~g}\right.\right.$ per coat $\div 60000$ g per mol $) \times$ Avogadro's number $]$. Since the volume of the coat, based on estimates from freezefracture studies (Erdos \& W'est, 1989), is approximately $2 \times 10^{10} \mathrm{~nm}^{3}$, there is a cube with an edge measuring $16 \mathrm{~nm}$ available for each protein, ignoring the space occupied by polysaccharide. Globular proteins of $M_{\mathrm{r}}$ 60000 would be expected to occupy volumes less than $20 \%$ of this value (Peters, 1986). Since crystalline cellulose is densely packed, this implies that protein may be loosely organized and well hydrated, which is consistent with the relatively low proportion of the hydrophobic amino acids $\mathrm{Ala}$, Ile, Leu, Val and Phe, and relatively high proportions of Thr, Ser, His and Pro, compared to values for the entire spore (Table 2, columns 3 and 2).

The two-dimensional gel analysis shows that there are nine major-abundance proteins and numerous, reproducibly detected, minor-abundance proteins (Table 3 ). However, only the proteins SP96, SP87, SP85, SP80, SP75, SP70 and SP60 have been shown to be present at similar levels and with similar apparent $M_{\mathrm{r}}$ and $\mathrm{pI}$ values in pregermination coats. Nevertheless, the remaining proteins listed are detected reproducibly and, altogether, the evidence suggests that the coat does not undergo dramatic changes in morphology and the biochemical composition of its protein components during germination. With the identification of SP75 as the product of the DP87 gene, the sequences of five such proteins are now known. Each is associated in some way with the outer layer of the coat as determined by proteolytic sensitivity and/or immunolocalization (Orlowski \& Loomis, 1979; West \& Erdos, 1988; Yoder et al., 1994). Though shared sequence motifs have been previously recognized in these proteins (Fosnaugh \& Loomis, 1989a, b; Ozaki et al., 1993; Powell-Coffman \& Firtel, 1994; Yoder et al., 1994), further comparisons across the entire group document a greater than previously recognized degree of homology. Amino acid analysis indicates that the remaining proteins have, on average, a lower content of Ser and Thr, a higher content of Pro and are more hydrophobic (Table 2).

From the extraction studies, it can be concluded that the interactions of the major proteins released by urea are, with the exception of SP96, stabilized by intermolecular as well as, presumably, intramolecular (see below) disulfide cross-links. Other types of covalent intermolecular crosslinking are not detectable, and divalent cations do not seem to be important for association of proteins with the coat. It is likely that coat protein disulfide bond formation occurs at multiple stages of the secretory pathway, as it does, for example, with von Willebrand's factor (Mayadas \& Wagner, 1992). At present, there is evidence for disulfide cross-linked intermolecular association prior to secretion in the prespore vesicle (Watson et al., 1993, 1994), but the composition of a proposed complex is open to question because artefactual disulfide bonds may have formed during isolation, and the composition of the complex does not predict the distribution of proteins in the spore coat as determined by epitope distribution (West \& Erdos, 1990). There is also evidence that some supramolecular assembly is extracellular, as some but not all proteins appear to freely and uniformly exchange between neighbouring spores during the assembly process (West \& Erdos, 1992). Whatever the nature of any precursor or final protein complex in the coat, four of the outer layer proteins are not essential to its formation (Nakao et al., 1994; Fosnaugh et al., 1995), as the remaining proteins still coassemble with cellulose to form coats in the gene deletion constructs, though they have increased porosity. 


\section{The five cloned outer layer spore coat genes encode a family of modular proteins}

Each of the cloned outer-layer-associated proteins is rich in Cys $(7 \cdot 4-13.2 \%)$, Pro $(5 \cdot 2-9 \cdot 9 \%)$, Ser and Thr (18.1-34.8\%; except for SP60), and deficient in the hydrophobic amino acids Phe, Val, Ile and Leu (9.3$15.6 \%$ ). Structure prediction algorithms suggest only short regions of secondary structure, consistent with the low percentage of hydrophobic residues available to stabilize folded domains. All five proteins possess a predicted signal peptide, which has been shown to be cleaved in all but SP87 (Table 3). Three categories of sequence repeats, involving Cys, Ser/Thr/Gly/Pro/Ala and Arg/Lys/Pro/His, respectively, span virtually the entire length of each protein.

There are five types of Cys repeats, distinguished by the spacing of their Cys residues (Table 5). The CC motif defines a landmark occurring exactly twice in each of the proteins except for SP60: the first begins at amino acid position 124-132 (relative to the Met start), and the second near the COOH-terminus (Fig. 6). The defining characteristic of the $\mathrm{CC}$ motif is the consensus sequence $\mathrm{Cys}_{2} \mathrm{Xxx}_{5} \mathrm{Cys}$ (Table 5). A second repeat, the $\mathrm{C} 2 \mathrm{C}$ motif (Table 5), is invariantly located immediately ahead of the second CC motif. The pair of CC motifs divides each protein into three regions: the $\mathrm{NH}_{2}$-terminal region (up to residue 124-132), the central region between the two $\mathrm{CC}$ motifs, and the COOH-region, which follows the second CC motif (Fig. 6). Each protein conforms to this scheme except for SP60, which lacks the landmark CC and $\mathrm{C} 2 \mathrm{C}$ motifs and consists only of the central region between them.

The $\mathrm{C} 7 \mathrm{C}$ repeat comprises the $\mathrm{NH}_{2}$-terminal regions (Fig. 6 ) of the four proteins which have $\mathrm{CC}$ and $\mathrm{C} 2 \mathrm{C}$ motifs. That the only homology among the 108 residue $\mathrm{C} 7 \mathrm{C}$ repeats from different proteins is the spacing of $12 \mathrm{Cys}$ residues (Table 5) suggests a critical pattern of disulfide bonds. Each central region is comprised of 4-13 C4C and $\mathrm{C} 3 \mathrm{C}$ motifs (Table 5), each averaging about 24 residues in length, interspersed with amino acid segments averaging 15 residues, which are generally but not always Cys-free (Fig. 6). As discussed below, these motifs may be related to EGF repeats. The intervening regions frequently consist of mucin-like (see below) and basic proline repeats. Basic proline repeats (Table 5) are 5-13 residues long and contain $>70 \%$ Arg, Lys, His and Pro. These repeats are similar in composition and spacing to those present in acidic proline-rich proteins from mammalian salivary glands (Ann et al., 1987), and are distinct from Pro-rich sequences found in plant matrix proteins. Finally, mucinlike repeats tend aiso to be clustered $\mathrm{COOH}$-terminal to the two landmark CC motifs (Fig. 6). SP70 and SP60 uniquely possess highly negatively charged stretches of 69 and 92 amino acids, containing $42-48 \%$ Asp and Glu residues, at their $\mathrm{COOH}$-termini (Fig. 6).

In conclusion, the primary structure of each protein can be summarized as a similar mosaic of sequence motifs (Fig. 6) which, as discussed below, are predicted to have discrete, characteristic secondary structures. The modular organization is reflected in the apparently vestigial retention of introns flanking the C7C repeat in the SP87 gene (Yoder et al., 1994); in the other genes, an intron separates the signal peptide, together with the four AsnGlyAspTrpAspAsp (N)-repeats (Fosnaugh \& Loomis, 1989b) of SP60, from the remainder of the protein. The overwhelming similarity of these five proteins, based on the order and identity of their shared motifs, confirms previous suggestions that they derive from a common ancestral gene. Examination of the relatedness of the landmark $\mathrm{C} 2 \mathrm{C}$ and $\mathrm{CC}$ repeats and the sequences and distribution patterns of the other motifs suggests that the SP70 gene is ancestral, that SP75 derives from SP70, and SP96 derives from SP75. The genes for SP96, SP87, SP70 and SP60 have remained in close proximity on the right hand end of chromosome 2 (Kuspa \& Loomis, 1996). However, the gene for SP75 maps to chromosome 4 (see Methods) by REMI-RFLP analysis (Kuspa \& Loomis, 1994). Since three previous coat genes have been named $\cot A-C$, we suggest that the DP87 gene be referred to as $\cot D$.

\section{The C2C, C4C and C3C sequence repeats resemble motifs from other proteins}

The $\mathrm{C} 3 \mathrm{C}$ and $\mathrm{C} 4 \mathrm{C}$ motifs each contain four Cys residues with the characteristic spacing 3/5/7-9 and 4/5/7-9 (number of residues between pairs of Cys residues), respectively. They consist minimally of about 24 residues including the flanking Cys residues, and occur 36 times in the 5 proteins (Table 5). The sequence CysProXxxGly or CysProProXxx, starting at the second Cys, and Cys $\mathrm{Xxx}_{3-5}$ Gly, starting at the third Cys, are consistent features of each motif. Of the numerous Cys-rich motifs recognized in extracellular proteins (Kieffer et al., 1994; Lecanidau et al., 1986; Hoffman \& Hauser, 1993; Wagner \& Wyss, 1994), the C3C and C4C repeats most resemble the $\mathrm{NH}_{2}$-terminal subdomain of EGF modules (Stenflo, 1991). The Cys-spacing in the C4C repeat is identical to the spacing of the first four of six Cys residues found in a major subgroup of EGF modules (Harris \& Spellman, 1993). The first four Cys residues of EGF modules, which contain about 42 amino acids, form a pair of disulfide bonds that stabilize the $\mathrm{NH}_{2}$-terminal subdomain, containing a characteristic hairpin $\beta$-motif consisting of two antiparallel $\beta$-strands separated by a $\beta$-turn (Graves $e t$ al., 1994). The third pair of Cys residues forms a disulfide bond which stabilizes a second smaller hairpin $\beta$-motif, part of the COOH-terminal subdomain, which associates with the $\mathrm{NH}_{2}$-subdomain. Thus, the $D$. discoideum motifs have Cys-spacing and other sequence characteristics of a truncated EGF module, consisting of the $\mathrm{NH}_{2}$ subdomain. If the $D$. discoideum motif folds in the same way as the full EGF module, the Gly residues of the CysProXxxGly and CysX $\mathrm{Xx}_{3-5}$ Gly subsequences are located at the turns flanking the first $\beta$-strand, positions which tend to be occupied by Pro and Gly residues in EGF modules. Furthermore, standard secondary structure algorithms predict, for the majority of $\mathrm{C} 3 \mathrm{C}$ and C4C motifs, the folding of the sequences immediately surrounding the third and fourth Cys residues into 
Table 5. Summary of sequence motifs in spore coat proteins

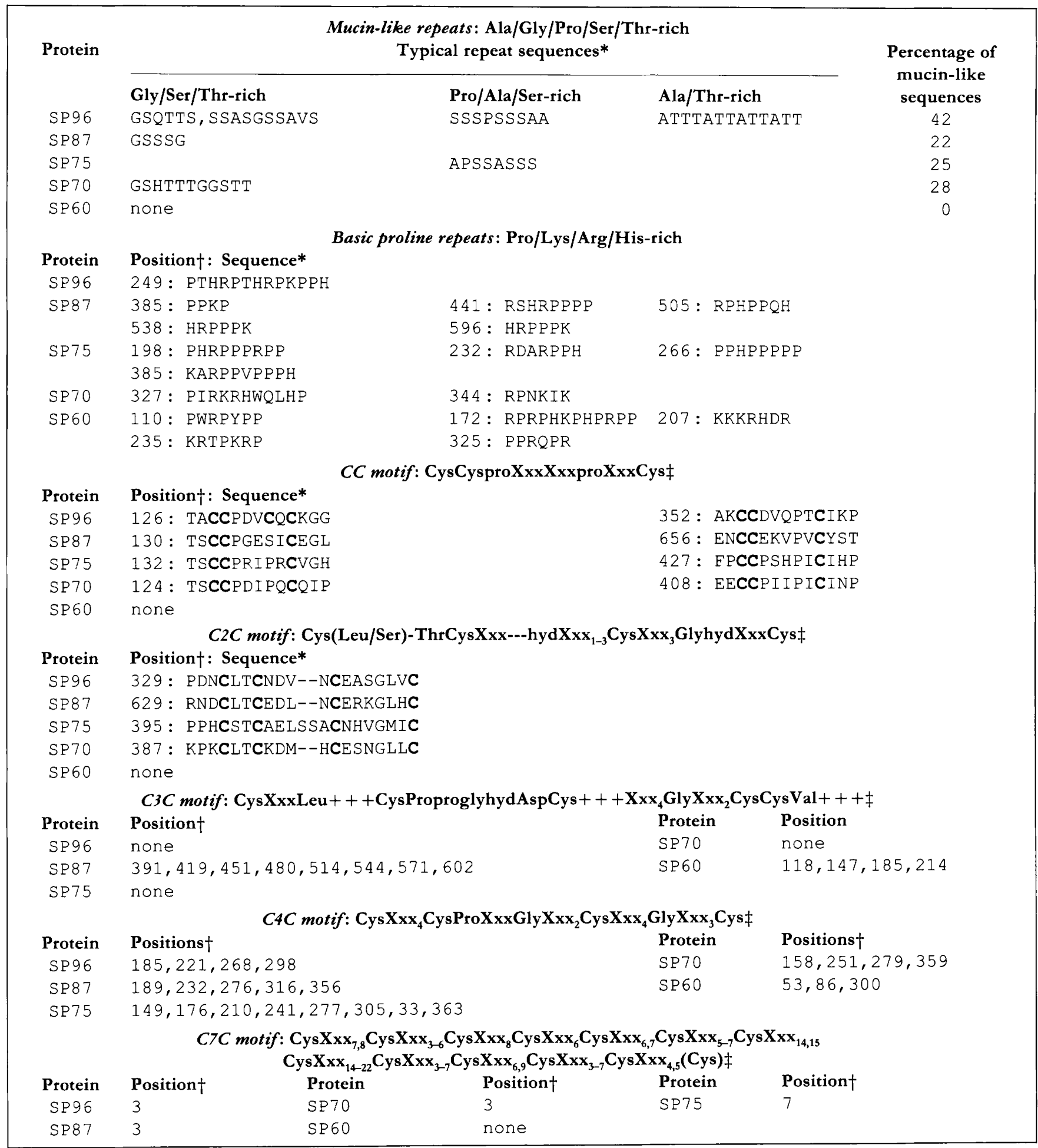

* Sequence examples are given in single-letter code.

$\dagger$ Position of the first residue of the motif in the complete protein sequence, including the signal peptide.

$\ddagger$ In the consensus sequences, upper-case indicates an invariant or nearly invariant residue; lower-case indicates a predominant residue; +++ , positively charged residue, ---, negatively charged residue; hyd, hydrophobic residue; Xxx, any amino acid; ( $)$, residue from a subsequent motif. 
SP96
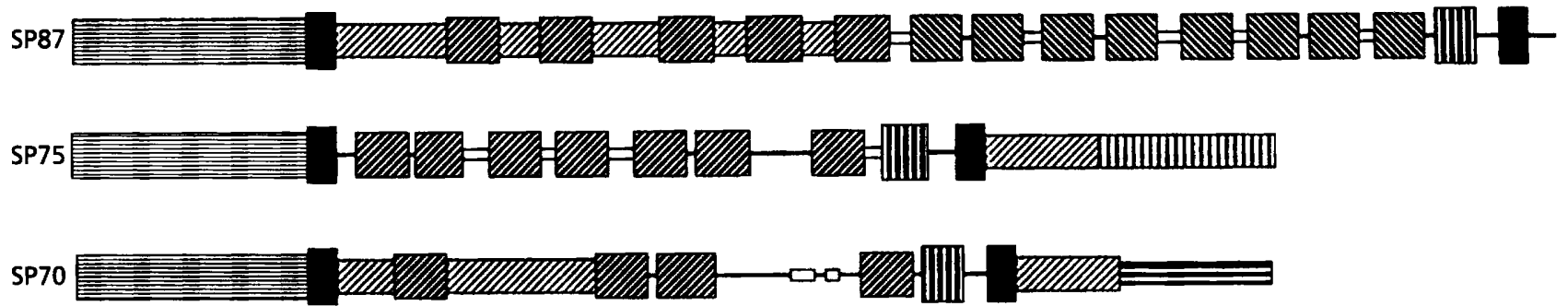

SP60

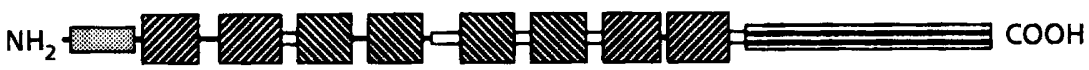

Key

Cys-repeats:
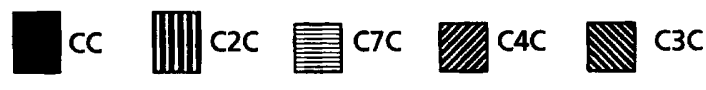

$\mathrm{C} 3 \mathrm{C}$

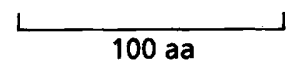

Mucin-like repeats:

GST IIIII)PSA AT

Other motifs:

Acidic

Basic proline

Fig. 6. Schematic diagram depicting the arrangement of sequence repeats in the five outer-layer-associated coat

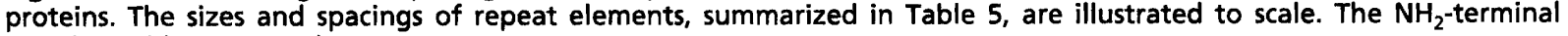
signal peptides are not shown.

antiparallel $\beta$-strands, the location at which this folding pattern occurs in normal EGF modules. Finally, EGF modules are the only location described for post-translational modification of Ser or Thr residues with single O-linked fucose residues (Harris \& Spellman, 1993). It is intriguing that SP96 and SP75, two of the coat proteins with multiple $\mathrm{C} 3 \mathrm{C}$ and $\mathrm{C} 4 \mathrm{C}$ motifs, also possess this $O$ fucose modification (Riley et al., 1993).

Although there is little sequence homology among different $\mathrm{C} 4 \mathrm{C}$ motifs aside from the key defining residues, sequence similarities imply an evolutionary path of divergence of this motif within and between proteins and possible pairwise duplication. Certain $\mathrm{C} 3 \mathrm{C}$ repeats are more closely related and occur in only two of the proteins, where they are tandemly clustered. A search of 70847 sequences of the PIR.41 protein sequence database revealed 477 matches for the Cys-spacing of C3C and C4C motifs. Most were in extracellular proteins, and those that do not lie in EGF modules represent potential homologues of the $D$. discoideum repeats. Full EGF modules occur tandemly repeated in vertebrate extracellular matrix glycoproteins, cell surface receptors, serum proteins and extracellular enzymes, where they appear to link other protein domains, assist in the presentation of domains and participate directly in ligand-receptor interactions (Engel, 1989; Stenflo, 1991).

The $\mathrm{C} 2 \mathrm{C}$ motif, which occurs once near the $\mathrm{COOH}$ terminus just upstream of the second $\mathrm{CC}$ motif, contains the subsequence CysLeuThrCys or CysSerThrCys. This spacing of Cys residues forms a disulfide bond at the active site of proteins of the thioredoxin family of oxidoreductases (Mayadas \& Wagner, 1992). Variation of the two inter-Cys residues changes the redox potential of DsbA, normally an extremely oxidizing member of the thioredoxin family, over a wide range. Substitutions by the residue pairs found in the spore coat protein $\mathrm{C} 2 \mathrm{C}$ motifs support a moderate oxidizing potential in this periplasmic protein of Escherichia coli (Grauschopf et al., 1995). The apparent interaction of coat proteins in an extended disulfide cross-linked array indicates a need for an extracellular disulfide isomerase activity which might be provided by these vicinal Cys residues.

\section{Ser/Thrrich sequence repeats resemble mucin motifs}

The Ser/Thr repeats, found in 4 of the 5 proteins (SP60 lacks this repeat type and the CC landmark motifs with which they tend to be associated), range from 6 to 13 residues in length (Table 5), and are often tandemly clustered. They contain exclusively Ser or Thr or a mixture of the two, and usually contain multiple Gly residues; Pro and Ala are also frequently present. The repeat sequence varies within and between proteins, but tends to be constant in a given contiguous stretch. A similar type of repeat occurs in a prespore cell-specific plasma membrane protein in which the number of repeats is polymorphic in different strains (Gooley et al., 1992). The repeats are similar to those in vertebrate epithelial mucins and other animal mucin-like proteins (Verma \& Davidson, 1994; Taylor-Papadimitriou \& Epenetos, 1994; Devine \& McKenzie, 1992), except for their relatively short length. Polymorphisms in mucin proteins have been attributed to the same genetic process of duplication and deletion. Coat proteins differ from vertebrate epithelial mucins, however, in their relatively 
small size, having reduced polypeptide $M_{\mathrm{r}}$ values of $5-7 \times 10^{4}$, vs $1-2 \times 10^{6}$ (Taylor-Papadimitriou \& Epenetos, 1994). Furthermore, a smaller percentage of the spore coat proteins is devoted to mucin-like repeats, ranging from $22-42 \%$ (Table 5) and, while many of these repeats are clustered in the coat proteins, smaller groups are also interspered between truncated EGF-like modules. Like coat proteins, many vertebrate mucins also possess $C y s-$ rich domains, at their $\mathrm{NH}_{2}$ - and $\mathrm{COOH}$-termini (Probst $e$ t al., 1990; Bhargava et al., 1990; Verma \& Davidson, 1993; Meerzaman et al., 1994; Gum et al., 1992; Hansson et al., 1994). Some possess characteristic Cys-spacing repeats (Hoffmann \& Hauser, 1993), and are disulfide cross-linked (Hansson et al., 1994). Though the $D$. discoideum mucin-like repeats have not yet been shown to share the extent of post-translational modifications typical of their mucin counterparts, two coat proteins, SP96 and SP75, exhibit $M_{\mathrm{r}}$ values which are much greater than the values predicted from their cDNA sequences (Table 3 ), and possess small $O$-linked oligosaccharides containing fucose and probably $N$-acetylglucosamine (Riley et al., 1993). Like vertebrate mucins (Taylor-Papadimitriou \& Epenetos, 1994), the coat proteins have very few $N$ glycans (Table 3). SP96 and SP75 are also phosphorylated on Ser residues (Akalehiywot \& Siu, 1983), with approximately 50 such modifications per copy of SP96 (Watson et al., 1993). This anionic modification of coat proteins may substitute for the sulfate and sialic acid modifications of vertebrate mucins. The fact that mucin-like repeats are found at the $\mathrm{COOH}$-terminus of some coat proteins (Fig. 6) in addition to internal positions suggests that they are not simple interdomain spacers.

\section{Spore coat protein sequence motifs are distinct from those of other $D$. discoideum matrix proteins}

Other $D$. discoideum matrix proteins, found in the stalk tube and in the slime sheath, share amino acid composition similarities with the spore coat proteins. The prestalk cellspecific and slime sheath matrix proteins ST430 (encoded by ecm B), ST310 (encoded by ecm A), D11 (encoded by D11), and sheathins possess characteristic Cys-repeats but these are distinct from those of coat proteins (Ceccarelli $e t$ al., 1987; Zhou-Chou et al., 1995), and basic proline and mucin-like repeats are not present. The prespore-specific PspB and EB4 proteins, which possibly reside in the coat and/or interspore matrix (Powell-Coffman \& Firtel, 1994; Hildebrandt et al., 1991), contain multiple C4C repeats and a small number of basic proline and $\mathrm{C} 3 \mathrm{C}$ repeats, but are devoid of $\mathrm{CC}, \mathrm{C} 2 \mathrm{C}$ and significant mucin-like repeats. The different sequence motifs of proteins from different $D$. discoideum extracellular matrices are consistent with the unique protein compositions of these matrices, and imply distinct functional attributes and mechanisms of intermolecular interactions for spore coat proteins.

\section{Protein function}

We suggest that the homologies between the outer layer coat proteins, and mucins, EGF modules and basic proline repeats form the basis of a model for the role of protein in coat morphogenesis. After coat protein secretion, formation of the protein bed might be initiated by ionic interactions between the basic proline repeats and the long anionic domains at the COOH-termini of two of the proteins. The mucin-like domains presumably assume extended, rod-like conformations (Gerken et al., 1989) which are spaced and may be kinked by knot-like truncated EGF modules. The mucin-like domains, together with the galuran polysaccharide, would be expected to support a hydrated, diffusion-limited microenvironment at the cell surface, which might assist in cell dehydration, compete for the cell--cell contacts (Hilkens $e t$ al., 1992) that formerly linked adjacent prespore cells together, and be favourable for the subsequent morphogenesis of the cellulose fibrils that form later. Since most coat proteins are soluble after secretion in the absence of cellulose (West \& Erdos, 1988) and remain soluble after extraction from the coat following dialysis (unpublished data), outer layer protein and cellulose may mutually organize each other's structures via the cellulosebinding activity of one coat protein (Zhang \& West, unpublished data). The protein bed may be stabilized by intermolecular disulfide cross-links formed after secretion, as seen in mucous coatings of epithelial cells (Verma \& Davidson, 1994). The absence of predictable tertiary structure of the proteins may facilitate disulfide bond migration from intrachain to interchain forms, catalysed by a single pair of vicinal Cys residues in four of the proteins during extracellular assembly. The degeneracy of the five coat proteins analysed here is more suited to the indeterminate, rather than crystalline, protein array postulated by this model. An indeterminate arrangement is consistent with the observation in the coat gene deletion strains that, with the exception of SP35, the remaining proteins appear to be incorporated normally (Figs 2, 5).

This model suggests how the coat can form near the plasma membrane without attaching to it (West \& Erdos, 1990), and why a normal-appearing coat forms when cells sporulate in monolayer culture after induction with 8bromoadenosine cAMP (unpublished data). However, it is possible that other proteins, perhaps associated with the inner layer of the coat, link the coat to the plasma membrane. The phenotypes of the deletion mutations, and the protein glycosylation mutations targeting $O$ glycosylation (West \& Erdos, 1990), might easily follow from changes in the amount or packing of cellulose fibrils. Because of the similarity and apparent redundancy of the outer layer coat proteins, it will be informative to delete additional members of this coat gene superfamily in order to probe how this type of protein contributes to cellulose morphogenesis.

\section{ACKNOWLEDGEMENTS}

Matt Presley and Wei-Ping Yuan are acknowledged for their excellent technical assistance. Gerry Shaw generously carried out database searches for repeat motifs. We are indebted to M. Tasaka, W.F. Loomis, J. Coffman-Powell, R. Firtel, R. Gomer, B. Yoder, D. Blumberg and K. Williams for sharing cell strains and antibodies. Steve Sugrue provided thoughtful commentary on the manuscript and Todd Barnash created the Fig. 6 graphic. 
This work was supported in part by NSF grant no. MCB9316897.

\section{REFERENCES}

Akalehiywot, T. \& Siu, C.-H. (1983). Phosphorylation of spore coat proteins of Dictyostelium discoideum. Can J Biochem Cell Biol 61, 996-1001.

Ann, D. K., Gadbois, D. \& Carlson, D. M. (1987). Structure, organization, and regulation of a hamster proline-rich protein gene. $J$ Biol Chem 262, 3958-3963.

Aparicio, J. G., Erdos, G. W. \& West, C. M. (1990). The spore coat is altered in modB glycosylation mutants of Dictyostelium discoideum. J Cell Biochem 42, 255-266.

Bhargava, A. K., Woitach, J. T., Davidson, E. A. \& Bhavanandan, V. P. (1990). Cloning and cDNA sequence of a bovine submaxillary gland mucin-like protein containing two distinct domains. Proc Natl Acad Sci US A 87, 6798-6802.

Ceccarelli, A., McRobbie, S. J., Jermyn, K. A., Duffy, K., Early, A. \& Williams, J. G. (1987). Structural and functional characterization of a Dictyostelium gene encoding a DIF inducible, prestalk-enriched mRNA sequence. Nucleic Acids Res 15, 7463-7476.

Cotter, D.A. (1981). Spore activation. In The Fungal Spore: Morphogenetic Controls, pp. 385-411. Edited by G. Turian \& H. R. Hohl, New York: Academic Press.

Creighton, T. E., Zapun, A. \& Darby, N. J. (1995). Mechanisms and catalysts of disulphide bond formation in proteins. Trends Biotechnol $13,18-23$.

Devine, P. L. \& McKenzie, I. F. C. (1992). Mucins: structure, function, and associations with malignancy. Bioessays 14, 619-625.

Devine, K. M., Morrissey, J. H. \& Loomis, W. F. (1982). Differential synthesis of spore coat proteins in prespore and prestalk cells of Dictyostelium. Proc Natl Acad Sci USA 79, 7361-7365.

Devine, K., Bergmann, J. \& Loomis W. F. (1983). Spore coat proteins of Dictyostelium discoideum are packaged in prespore vesicles. Dev Biol 99, 437-446.

Dupont, E., El Aoumari, A., Briand, J. P., Fromaget, C. \& Gros, D. (1989). Cross-linking of cardiac gap junction connexons by thiol/disulfide exchanges. J Membr Biol 108, 247-252.

Engel, L. (1989). EGF-like domains in extracellular matrix proteins: localized signals for growth and differentiation? FEBS Lett 251, $1-7$.

Erdos, G. W. \& Whitaker, D. (1983). Failure to detect immunocytochemically reactive endogenous lectin on the cell surface of Dictyostelium discoideum. J Cell Biol 97, 993-1000.

Erdos, G. W. \& West, C. M. (1989). Formation and organization of the spore coat of Dictyostelium discoideum. Exp Mycol 13, 169-182.

Fosnaugh, K. L. \& Loomis, W. F. (1989a). Sequence of the Dictyostelium discoideum spore coat gene SP96. Nucleic Acids Res 17, 9489.

Fosnaugh, K. L. \& Loomis, W. F. (1989b). Spore coat genes SP60 and SP70 of Dictyostelium discoideum. Mol Cell Biol 9, 5215-5218.

Fosnaugh, K. L., Fuller, D. \& Loomis, W. F. (1995). Structural roles of the spore coat proteins in Dictyostelium discoideum. Dev Biol 166, 823-825

Freeze, H. H. (1996). Dictyostelium discoideum glycoproteins: using a model system for organismic glycobiology. In New Comprehensive Biochemistry, Ch. 20. Edited by A. Neuberger \& L. L. M. Van Deenen. Cambridge: Elsevier (in press).

Gerken, T. A., Butenhof, K. J. \& Shogren, R. (1989). Effects of glycosylation on the conformation and dynamics of $O$-linked glycoproteins: carbon-13 NMR studies of ovine submaxillary mucin. Biochemistry 28, 5536-5543.

Gonzalez-Yanes, B., Mandell, R. B., Girard, M., Henry, S., Aparicio, O., Gritzali, M., Brown, R. D., Erdos, G. W. \& West, C. M. (1989). The spore coat of a fucosylation mutant in Dictyostelium discoideum. Dev Biol 133, 576-587.

Gooley, A. A., Marschchalek, R. \& Williams, K. L. (1992). Size polymorphisms due to changes in the number of $O$-glycosylated tandem repeats in the Dictyostelium discoideum glycoprotein PsA. Genetics 130, 749-756.

Grauschopf, U., Winther, J. R., Korber, P., Zander, T., Dallinger, P. \& Bardwell, J. C. A. (1995). Why is DsbA such an oxidizing disulfide catalyst? Cell 83, 947-955.

Graves, B. J., Crowther, R. L., Chandran, C., Rumberger, J. M., Li, S., Huang, K.-S., Presky, D. H., Familletti, P. C., Wolitzky, B. A. \& Burns, D. K. (1994). Insight into E-selectin/ligand interaction from the crystal structure and mutagenesis of the lec/EGF domains. Nature 367, 532-538.

Gum, J. R., Hicks, J. W., Toribara, N., Rothe, E.-M., Lagace, R. E. \& Kim, Y. S. (1992). The human MUC2 intestinal mucin has cyteinerich subdomains located both upstream and downstream of its central repetitive region. J Biol Chem 267, 21375-21383.

Haberstroh, L. \& Firtel, R. A. (1990). A spatial gradient of expression of a cAMP-regulated prespore cell-type-specific gene in Dictyostelium. Genes Dev 4, 596-612.

Hansson, G. C., Baeckstrom, D., Caristedt, I. \& Klinga-Levan, K. (1994). Molecular cloning of a cDNA coding for a region of an apoprotein from the 'insoluble' mucin complex of rat small intestine. Biochem Biophys Res Commun 198, 181-190.

Harris, R. J. \& Spellman, M. W. (1993). O-linked fucose and other post-translational modifications unique to EGF modules. Glycobiology 3, 219-224.

von Heijne, G. (1985). Signal sequences: the limits of variation. J Mol Biol 184, 99-105.

Hildebrandt, M., Humbel, B. M. \& Nellen, W. (1991). The Dictyostelium discoideum EB4 gene product and a truncated mutant form of the protein are localized in prespore vesicles but absent from mature spores. Dev Biol 144, 212-214.

Hilkens, J., Ligtenberg, M. J. L., Vos, H. L. \& Litvinov, S. V. (1992). Cell membrane-associated mucins and their adhesion-modulating properties. Trends Biochem Sci 17, 359-363.

Hoffmann, W. \& Hauser, F. (1993). The P-domain or trefoil motif: a role in renewal and pathology of mucous epithelia? Trends Biochem Sci 18, 239-243.

John, S. A. \& J.-P. Revel (1991). Connexon integrity is maintained by non-covalent bonds: intramolecular disulfide bonds link the extracellular domains in rat connexin-43. Biocbem Biophys Res Commun 178, 1312-1318.

Kieffer, B., Driscoll, P. C., Campbell, I. D., Willis, A. C., van der Merwe, P. A. \& Davis, S. J. (1994). Three-dimensional solution structure of the extracellular region of the complement regulatory protein CD59, a new cell-surface protein domain related to snake venom neurotoxins. Biochemistry 33, 4471-4482.

Kozarov, E., van der Wel, H., Field, M., Gritzali, M., Brown, R. D. \& West, C. M. (1995). Characterization of FP21, a cytosolic glycoprotein from Dictyostelium. J Biol Chem 270, 3022-3030.

Kuspa, A. \& Loomis, W. F. (1994). REMI-RFLP mapping in the Dictyostelium genome. Genetics 138, 665-674.

Kuspa, A. \& Loomis, W. F. (1996). Ordered yeast artificial chromosome clones representing the Dictyostelium discoideum genome. Proc Natl Acad Sci USA 93, 5562-5566. 
Lenhard, J. M., Siegel, A. \& Free, S. J. (1989). Developing Dictyostelium cells contain the lycosomal enzyme $\alpha$-mannosidase in a secretory granule. J Cell Biol 109, 2761-2769.

Lydan, M. A. \& Cotter, D. A. (1994). Spore swelling in Dictyostelium is a dynamic process mediated by calmodulin. FEMS Microbiol Lett $115,137-142$.

Mayadas, T. N. \& Wagner, D. D. (1992). Vicinal cysteines in the prosequence play a role in von Willebrand factor multimer assembly. Proc Natl Acad Sci USA 89, 3531-3535.

Meerzaman, D., Charles, P., Daskal, E., Polymeropoulos, M. H., Martin, B. M. \& Rose, M. C. (1994). Cloning and analysis of cDNA encoding a major airway glycoprotein, human tracheobronchial mucin (MUC5). J Biol Chem 169, 12932-12939.

Nakao, H., Yamamoto, A., Takeuchi, I. \& Tasaka, M. (1994). Dictyostelium prespore-specific gene (DP87) encodes a sorus matrix protein. J Cell Sci 107, 397-403.

Orlowski, M. \& Loomis, W. F. (1979). Plasma membrane proteins of Dictyostelium: the spore coat proteins. Dev Biol 71, 297-307.

Ozaki, T., Nakao, H., Orii, H., Morio, T., Takeuchi, I. \& Tasaka, M. (1993). Developmental regulation of transcription of a novel prespore-specific gene (DP87) in Dictyostelium discoideum. Development 117, 1299-1308.

Peters, R. (1986). Fluorescence microphotolysis to measure nucleocytoplasmic transport and intracellular mobility. Biochim Biophys Acta 864, 305-359.

Ploug, M., Jensen, A. L. \& Barkholt, V. (1989). Determination of amino acid compositions and $\mathrm{NH}_{2}$-terminal sequences of peptides electroblotted onto PVDF membranes from tricine-sodium dodecyl sulfate-polyacrylamide gel electrophoresis: application to peptide mapping of human complement component C3. Anal Biochem 181, 33-39.

Powell-Coffman, J. A. \& Firtel, R. A. (1994). Characterization of a novel Dictyostelium discoideum prespore-specific gene, $\mathrm{PspB}$, reveals conserved regulatory sequences. Development 120, 1601-1611.

Probst, J. C., Gertzen, E.-M. \& Hoffmann, W. (1990). An integumentary mucin (FIM-B.1) from Xenopus laevis homologous with von Willebrand factor. Biochemistry 29, 6240-6244.

Riley, G. R., West, C. M. \& Henderson, E. J. (1993). Cell differentiation in Dictyostelium discoideum controls assembly of proteinlinked glycans. Glycobiology 3, 165-177.

Seshadri, J., Dimond, R. \& Cotter, D. (1986). The characterization and secretion pattern of the lycosomal trehalases of Dictyostelium discoideum. Exp Mycol 10, 131-143.

Stenflo, J. (1991). Structure-function relationships of epidermal growth factor modules in vitamin $\mathrm{K}$-dependent clotting factors. Blood 78, 1637-1651.

Stone, K. L. \& Williams, K. R. (1993). Enzymatic digestion of proteins and HPLC peptide isolation. In A Practical Guide to Protein and Peptide Purification for Microsequencing, 2nd edn, pp. 43-69. Edited by P. Matsudaira. San Diego: Academic Press.
Tasaka, M., Hasegawa, M., Ozaki, T., Iwabuchi, M. \& Takeuchi, I. (1990). Isolation and characterization of spore coat protein (SP96) gene of Dictyostelium discoideum. Cell Differ Dev 31, 1-9.

Taylor-Papadimitriou \& Epenetos, A. A. (1994). Exploiting altered glycosylation patterns in cancer, progress and challenges in diagnosis and therapy. Trends Biotechnol 12, 227-233.

Verma, M. \& Davidson, E. A. (1993). Molecular cloning and sequencing of a canine tracheo-bronchial mucin cDNA containing a cysteine-rich domain. Proc Natl Acad Sci US A 90, 7144-7148.

Verma, M. \& Davidson, E. A. (1994). Mucin genes: structure, expression and regulation. Glycoconj J 11, 172-179.

Wagner, G. \& Wyss, D. F. (1994). Cell surface adhesion receptors. Curr Opin Struct Biol 4, 841-851.

Watson, N., Williams, K. L. \& Alexander, S. (1993). A developmentally regulated glycoprotein complex from Dictyostelium discoideum. J Biol Chem 268, 22634-22641.

Watson, N., McGuire, V. \& Alexander, S. (1994). The PsB glycoprotein is secreted as a preassembled precursor of the spore coat in Dictyostelium discoideum. J Cell Sci 107, 2567-2579.

West, C. M. \& Erdos, G. W. (1988). The expression of glycoproteins in the extracellular matrix of the cellular slime mold Dictyostelium discoideum. Cell Differ 23, 1-16.

West, C. M. \& Erdos, G. W. (1990). Formation of the Dictyostelium spore coat. Dev Genet 11, 492-506.

West, C. M. \& Erdos, G. W. (1992). Incorporation of protein into spore coats is not cell-autonomous in Dictyostelium. J Cell Biol 116, $1291-1300$

West, C. M. \& Loomis, W. F. (1985). Absence of a carbohydrate modification does not affect the level or subcellular localization of three membrane glycoproteins in modB mutants of Dictyostelium discoideum. J Biol Chem 260, 13803-13809.

Wilkinson, D. G. \& Hames, B. D. (1983). Characterisation of the spore coat proteins of Dictyostelium discoideum. Eur J Biochem 129, 637-643.

Wray, W., Boulikas, T., Wray, V. P. \& Hancock, R. (1981). Silver staining of proteins in polyacrylamide gels. Anal Biochem 118, 197-203.

Yoder, B. K., Mao, J., Erdos, G. W., West, C. M. \& Blumberg, D. D. (1994). Identification of a new spore coat protein gene in the cellular slime mold Dictyostelium discoideum. Dev Biol 163, 49-65.

Yurchenko, P. D., Cheng, Y.-S. \& Colognato, H. (1992). Laminin forms an independent network in basement membranes. J Cell Biol $117,1119-1133$.

Zhou-Chou, T., Wilkins, M. R., Vardy, P. H., Gooley, A. A. \& Williams, K. L. (1995). Glycoprotein complexes interacting with cellulose in the 'cell print' zones of the Dictyostelium discoideum extracellular matrix. Dev Biol 168, 332-341.

Received 14 February 1996; revised 21 March 1996; accepted 28 March 1996. 